\title{
Composição florística e distribuição altitudinal de epífitas vasculares da Floresta Ombrófila Densa na Serra da Prata, Morretes, Paraná, Brasil
}

\author{
Christopher Thomas Blum ${ }^{1,2}$, Carlos Vellozo Roderjan ${ }^{1}$ \& Franklin Galvão ${ }^{1}$ \\ ${ }^{1}$ Programa de Pós-graduação em Engenharia Florestal, Universidade Federal do Paraná - UFPR, \\ Av. Pref. Lothário Meissner, 900, Jardim Botânico, Campus III, CEP 80210-170, Curitiba, PR, Brasil \\ ${ }^{2}$ Autor para correspondência: Christopher Thomas Blum, e-mail: blumct@gmail.com
}

BLUM, C.T., RODERJAN, C.V. \& GALVÃO, F. Floristic composition and altitudinal distribution of vascular epiphytes in the Ombrophilous Dense Forest of the Prata Mountain Range, Morretes, Paraná State, Brazil. Biota Neotrop. 11(4): http://www.biotaneotropica.org.br/v11n4/en/abstract?inventory+bn00811042011

\begin{abstract}
The floristic survey of vascular epiphytes was done in the northern part of the Prata Mountain Range ( $48^{\circ} 41^{\prime}$ '59.39" W and 25 36' 46.39' S), Morretes municipality, comprising 6.3 ha of a slope between 400 and $1,100 \mathrm{~m}$ a.s.l., covered by submontane and montane Atlantic Rainforest. The aims of this study were: 1) characterize the vascular epiphytic flora; 2) discuss the species distribution along the slope and in ecological categories; 3) evaluate the floristic similarity among the study area and other forests of South and Southeastern Brazil. The present survey was carried out between 2005 and 2010. One hundred twenty phorophytes were climbed and closely examined. Two hundred seventy-eight species, 109 genus and 30 families of vascular epiphytes were recorded. Pteridophytes comprised 74 species, 30 genus and 10 families. Angiosperms comprised 204 species, 79 genus and 20 families. The vascular epiphytic richness was the highest registered in studies of Atlantic Rainforest in South Brazil. Seven species were the first records for the Paraná State and six are threatened considering the Paraná state official list of endangered species. Orchidaceae was de richest family, with 103 (37.2\%) species and $43(39.1 \%)$ genus, followed by Bromeliaceae (38), Polypodiaceae (28), Hymenophyllaceae (15), Araceae (14) and Piperaceae (14). The holoepiphytes were the dominant group, comprising $83 \%$ of the total. Only 54 (19.5\%) species were recorded in all altitudinal belts. Other $131(47.3 \%)$ species were recorded only under the $700 \mathrm{~m}$ a.s.1. and $54(19.5 \%)$ were found just above the $800 \mathrm{~m}$ a.s.l. The floristic similarity between the two extremities of the studied slope was low, showing the importance of the altitude for the species distribution. The epiphytic flora of the Prata Mountain Range presented low similarity with others Atlantic Rainforest communities of Paraná and São Paulo states.
\end{abstract}

Keywords: Atlantic Rainforest, montane, submontane, richness, altitudinal gradient.

BLUM, C.T., RODERJAN, C.V. \& GALVÃO, F. Composição florística e distribuição altitudinal de epífitas vasculares da Floresta Ombrófila Densa na Serra da Prata, Morretes, Paraná, Brasil. Biota Neotrop. 11(4): http://www.biotaneotropica.org.br/v11n4/pt/abstract?inventory+bn00811042011

Resumo: O levantamento de epífitas vasculares foi realizado na porção norte da Serra da Prata (48 41'59,39" O e $25^{\circ} 36^{\prime}$ 46,39” S), município de Morretes, abrangendo 6,3 ha de encosta situada entre 400 e 1.100 m s.n.m., coberta por Floresta Ombrófila Densa Submontana e Montana. Os objetivos do trabalho foram: 1) caracterizar a flora epifítica vascular; 2) discutir sua distribuição altitudinal e nas categorias ecológicas; 3) avaliar a similaridade florística com outras áreas do sul e sudeste do Brasil. O levantamento foi efetivado entre 2005 e 2010. Cento e vinte forófitos, distribuídos por quatro altitudes $(400,600,800$ e $1.000 \mathrm{~m})$, foram escalados e detalhadamente vasculhados. Foram registradas 278 espécies, 109 gêneros e 30 famílias de epífitas vasculares. Pteridófitas englobaram 74 espécies, 30 gêneros e 10 famílias. Angiospermas totalizaram 204 espécies, 79 gêneros e 20 famílias. A riqueza de epífitas vasculares foi a maior já registrada em estudos de Floresta Ombrófila Densa no sul do Brasil. Sete espécies tiveram seu primeiro registro para o Paraná e seis enquadraram-se como ameaçadas em nível estadual. Orchidaceae foi a mais rica, com 103 (37,2\%) espécies e 43 (39,1\%) gêneros, seguida de Bromeliaceae (38), Polypodiaceae (28), Hymenophyllaceae (15), Araceae (14) e Piperaceae (14). As holoepífitas características constituíram o grupo dominante, perfazendo $83 \%$ do total. Apenas 54 (19,5\%) espécies foram registradas em todas as faixas altitudinais, sendo que 131 (47,3\%) foram registradas somente abaixo dos $700 \mathrm{~m}$ e 54 (19,5\%) encontradas somente acima dos $800 \mathrm{~m}$. Detectou-se reduzida similaridade florística entre as extremidades da encosta estudada, o que destaca a importância da altitude na distribuição das espécies. A flora epifítica da Serra da Prata apresentou reduzida similaridade com outras comunidades de Floresta Ombrófila Densa do PR e SP. Palavras-chave: Floresta Pluvial Atlântica, montana, submontana, riqueza, gradiente altitudinal. 


\section{Introdução}

A Floresta Ombrófila Densa é a fisionomia vegetal predominante na região costeira do sul do País (Instituto... 1992). Fatores climáticos, como temperatura e umidade elevadas, além da precipitação bem distribuída ao longo do ano, proporcionam a exuberância da vegetação, não só em relação ao porte dos indivíduos ou à rapidez de seu desenvolvimento, mas também em função da elevada riqueza de espécies. Sua situação em zona extratropical no sul do País não lhe impede de apresentar fisionomia essencialmente tropical, incorrendo apenas na ausência de algumas espécies típicas e, por outro lado, na potencialização de endemismos. A diversificação ambiental resultante da interação de múltiplos fatores abióticos é um importante aspecto desta região fitoecológica, com considerável influência sobre a dispersão de espécies e o desenvolvimento estrutural da floresta, resultando em fisionomias distintas (Wettstein 1970, Leite \& Klein 1990).

De um modo geral, pode-se dividir as fisionomias de Floresta Ombrófila Densa Atlântica em dois grandes grupos, de acordo com seu embasamento geológico e sua posição na paisagem. $\mathrm{O}$ primeiro grupo ocorre sobre planícies sedimentares do Cenozóico e compreende as formações Aluvial, Terras Baixas e Submontana, esta última sobre depósitos coluviais. O segundo grupo ocorre sobre conjuntos montanhosos ou sistemas de dobramento embasados por rochas do Pré-Cambriano, abrangendo as formações Submontana, Montana e Altomontana (Instituto... 1992, Leite 2002, Roderjan et al. 2002). A Serra da Prata é caracterizada por este segundo grupo fisionômico, que no presente estudo foi tratado como Floresta Ombrófila Densa de encosta.

Nas porções inferiores e intermediárias da Serra da Prata ocorrem as formações Submontana e Montana, respectivamente, cada uma com características estruturais e florísticas determinadas pela variação de condicionantes abióticas como clima, relevo e solos. O limite entre estas duas formações é representado por uma comunidade transicional que ocupa uma faixa altitudinal situada entre as cotas de 600 e 800 m s.n.m. (Blum \& Roderjan 2007).

A despeito das boas condições de conservação em que se encontram as áreas de Floresta Ombrófila Densa Submontana e Montana no Paraná, existem ainda poucos estudos sobre sua composição florística e estrutural, sendo a maior parte focada no componente arbóreo-arbustivo (Silva 1994, Guapyassú 1994, Roderjan 1994, Athayde 1997, Lacerda 1999, Schorn \& Galvão 2001, Blum 2006, Reginato \& Goldenberg 2007).

Sabe-se, no entanto, que as demais sinúsias que compõem as florestas pluviais representam grande fatia de sua riqueza florística total, sendo particularmente relevantes as epífitas vasculares. Para uma floresta pluvial tropical do Equador, Gentry \& Dodson (1987a) descrevem que espécies de epífitas vasculares representam $23 \%$ da flora local. Na Costa Rica, Hartshorn \& Hammel (1994) encontraram proporção semelhante, $26 \%$ dentre todas as espécies nativas registradas. No Brasil, Lima \& Guedes-Bruni (1997) demonstraram que as epífitas podem representar $30 \%$ de toda a flora vascular de uma floresta pluvial tropical, enquanto Kersten \& Silva (2006) registraram percentual ainda mais elevado, de $51 \%$ em uma floresta de planície litorânea. No entanto, apesar de um aumento relativo no número de trabalhos abrangendo a florística e ecologia de epífitas, concentrados nos últimos anos, estes ainda são escassos perante a importância ecológica que estas possuem como elementos estruturais em florestas pluviais (Nadkarni 1984, Nieder et al. 2000).

A escassez de estudos sobre epifitismo vascular torna-se ainda mais acentuada quando considerados somente trabalhos realizados no âmbito da Floresta Ombrófila Densa de encosta, pela dificuldade de acesso na maioria dos casos e pelo porte de suas árvores, entre outros fatores. No Brasil, como trabalhos que abordaram epifitismo em Floresta Ombrófila Densa de encosta, pode-se citar Fontoura et al. (1997), no Rio de Janeiro; Breier (2005), em São Paulo; Schütz-Gatti (2000) e Petean (2002, 2009), no Paraná; Mancinelli \& EsemannQuadros (2007), em Santa Catarina; Reis \& Fontoura (2009), na Bahia. Além destes existem também trabalhos que abordaram áreas de contato entre outras fitofisionomias florestais e a Floresta Ombrófila Densa de encosta, é o caso de Santos (2008), em São Paulo, e Kersten \& Kuniyoshi (2006), no Paraná.

O presente estudo teve como objetivos: caracterizar qualitativamente o componente epifítico vascular de um trecho de Floresta Ombrófila Densa situado entre os 400 e os 1.100 m s.n.m. numa encosta da porção norte da Serra da Prata, Morretes, Paraná; discutir a distribuição das espécies nas categorias ecológicas e ao longo do gradiente de altitude; e efetuar comparações florísticas entre esta e outras áreas florestais no sul e sudeste do Brasil.

\section{Material e Métodos}

\section{Caracterização da área de estudo}

A encosta estudada localiza-se na face norte da Torre da Prata (Figura 2a), ponto culminante da Serra da Prata, dentro do município de Morretes, Paraná (Figura 1). A maior parte da Serra da Prata é abrangida pelo Parque Nacional Saint-Hilaire/Lange, com 25.000 ha (Siedlecki et al. 2003).

A área onde foram realizados os levantamentos qualitativos situase entre as cotas 400 e 1.100 m s.n.m. (Figura 2b), abrangendo cerca de 6,3 ha ao longo da trilha de acesso à Torre da Prata $\left(48^{\circ} 41^{\prime} 59,39^{\prime \prime} \mathrm{O}\right.$ e $25^{\circ} 36^{\prime} 46,39^{\prime \prime}$ ). O embasamento geológico é constituído pelo Granito Rio do Poço (Lopes 1987). Nos pisos superiores ocorrem Neossolos Litólicos e Cambissolos rasos; os trechos intermediários e inferiores são caracterizados por Cambissolos gradualmente mais profundos, podendo, eventualmente, ocorrer também Argissolos (Curcio 1992, Blum 2006).

De acordo com a classificação de Koeppen, a área é abrangida por dois tipos climáticos: abaixo dos $700 \mathrm{~m}$ s.n.m. o clima Cfa, subtropical úmido mesotérmico e com verões quentes; e acima do referido patamar o clima $\mathrm{Cfb}$, subtropical superúmido mesotérmico, com médias térmicas mais baixas e a possível ocorrência de geadas no inverno. A região é caracterizada por índices pluviométricos que variam entre 2.000 a $3.000 \mathrm{~mm}$, com média anual de $2.290 \mathrm{~mm}$ (Instituto... 1978, Blum et al. 2011).

A Serra da Prata é coberta por Floresta Ombrófila Densa, representada no trecho do estudo pelas formações Submontana e Montana, assim como por uma comunidade transicional entre as duas. A área estudada se encontra em bom estado de conservação, apresentando características de floresta primária pouco alterada (Blum 2006).

\section{Coleta e análise de dados}

O levantamento florístico foi realizado ao longo e a partir da trilha de acesso ao cume da Torre da Prata. A prospecção de espécies se restringiu à faixa altitudinal situada entre as cotas $400 \mathrm{e}$ $1.100 \mathrm{~m}$. Ao longo da referida trilha, a cada $100 \mathrm{~m}$ de desnível altitudinal (400, 500, 600, 700, 800, 900, 1.000 e $1.100 \mathrm{~m}$ ), foram delimitados oito sítios com área aproximada de $2.000 \mathrm{~m}^{2}$, onde foram concentrados os esforços de observações e coleta de material botânico. Adicionalmente, também foram considerados os registros e coletas realizados durante os deslocamentos ao longo dos $2.320 \mathrm{~m}$ da trilha de acesso, em geral abrangendo uma faixa de $10 \mathrm{~m}$ para cada lado da mesma. 


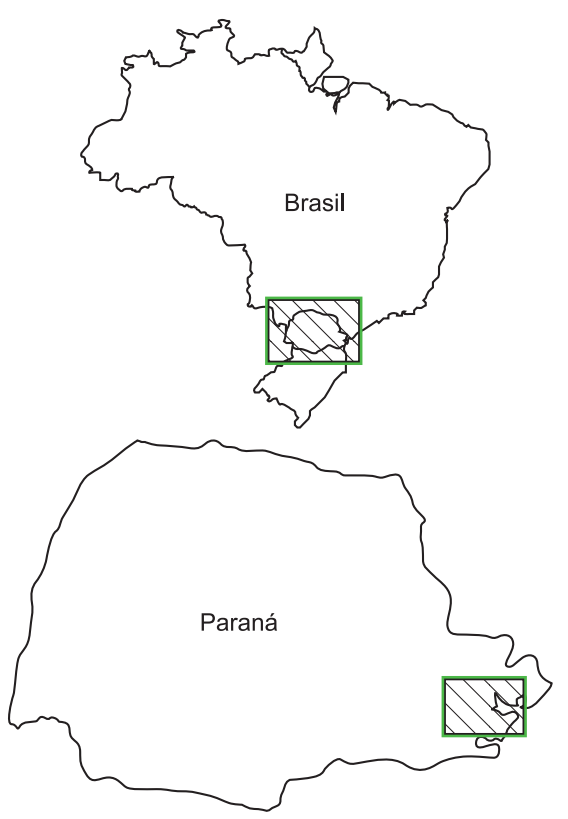

Figura 1. Localização da área de estudo (Serra da Prata).

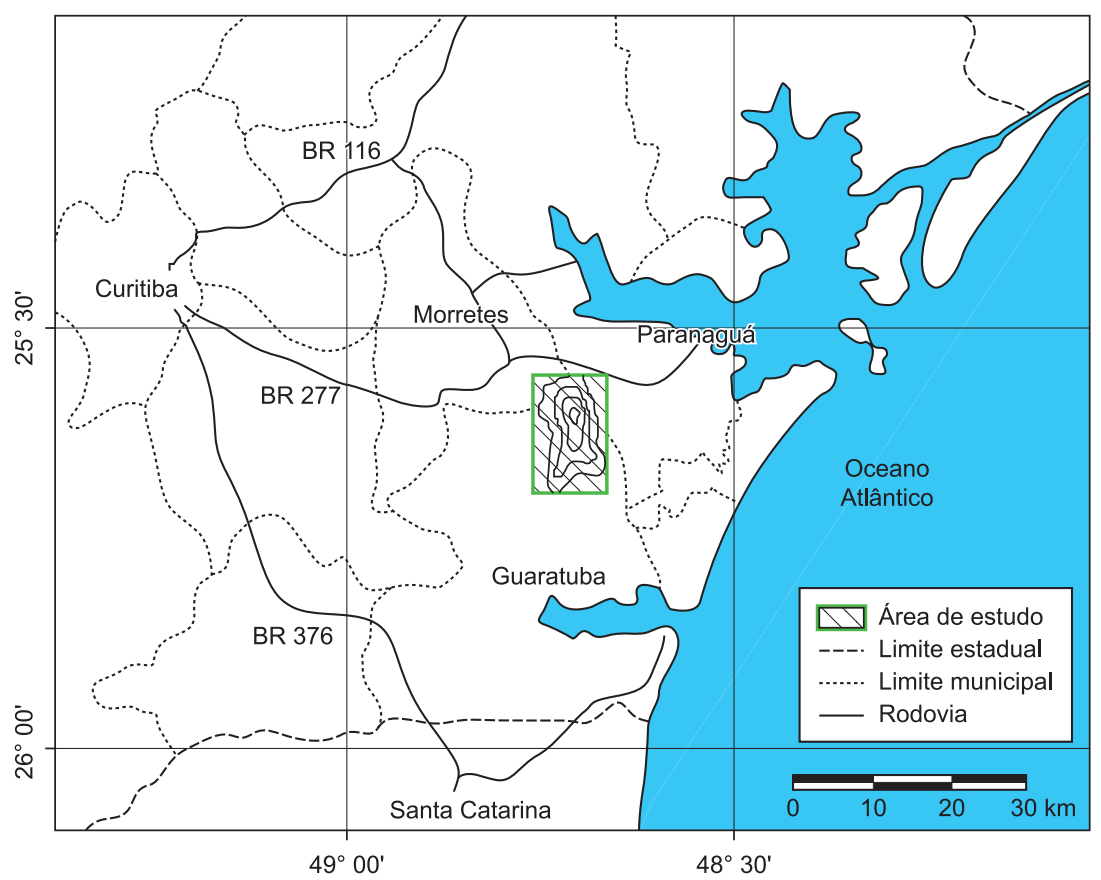

Figure 1. Location of the studied area (Prata Mountain Range).

O levantamento qualitativo baseou-se primordialmente em 57 dias de coletas intensivas em campo entre setembro de 2008 e janeiro de 2010. Registros fotográficos e coletas botânicas obtidos durante incursões realizadas entre 2005 e 2007 também foram incluídos.

Grande parte das coletas e registros foi obtida através da escalada de 120 forófitos distribuídos equitativamente nas cotas 400, 600, 800 e $1.000 \mathrm{~m}$. Nos demais trechos da encosta estudada, os registros foram efetivados geralmente ao nível do solo, a partir de visualizações a olho nu ou com auxílio de binóculo, e também através de verificações detalhadas de árvores e galhos recém caídos.

Procurou-se coletar pelo menos um exemplar fértil da maior parte das espécies epífitas vasculares encontradas. Espécies muito comuns e de taxonomia conhecida foram registradas somente através de fotografias digitais, sendo que a cada imagem obtida foi atrelado o referenciamento da altitude onde se efetuou o registro, procedimento igual ao realizado nas coletas de material botânico. Em muitos casos foi necessária a coleta de exemplares em estado vegetativo, especialmente da família Orchidaceae, os quais foram cultivados até seu florescimento em casa de vegetação construída especificamente para este fim.

As coletas obtidas foram fotografadas e herborizadas seguindo os procedimentos usuais, conforme IBGE (Instituto... 1992), para posterior identificação e tombamento no Museu Botânico Municipal de Curitiba-MBM e no Herbário do Departamento de Botânica da Universidade Federal do Paraná-UPCB.

A identificação foi realizada com auxílio de literatura taxonômica, comparação com material depositado nos herbários MBM e UPCB e através da consulta a especialistas. Para complementar a lista de espécies foi realizada pesquisa do acervo nos herbários MBM e UPCB, através do Specieslink (2010), sendo incluídos alguns registros referentes a coletas obtidas na mesma área de estudo. As angiospermas foram organizadas segundo o sistema APG III (Angiosperm...2009) e as pteridófitas conforme Smith et al. (2006) para Monilophyta e Tryon \& Tryon (1982) para Lycophyta. A validade dos nomes das espécies e a abreviatura dos autores foram verificadas em Tropicos (2009). As sinonímias de angiospermas foram verificadas em World Checklist of Selected Plant Families (2009) e, para pteridófitas, em Zuloaga et al.
(2008). O status de vulnerabilidade das espécies registradas foi checado através da consulta a listas de espécies ameaçadas (Paraná 1995, Fundação... 2005, Giulietti et al. 2008, International... 2011).

As epífitas registradas foram enquadradas em seis categorias ecológicas, de acordo com a relação que mantêm com o forófito (Benzing 1990, Kersten \& Silva 2005): holoepífitos obrigatórios (HLO) e holoepífitos preferenciais (HLP), ambos considerados holoepífitos característicos; holoepífitos facultativos (HLF); holoepífitos acidentais (HLA); hemiepífitos primários (HMP); e hemiepífitos secundários (HMS).

A riqueza de espécies registrada na Serra da Prata foi comparada aos resultados de outros 17 estudos sobre epífitas vasculares realizados no Paraná, Santa Catarina, São Paulo, Rio Grande do Sul (Hertel 1949, Waechter 1986, 1992, Schütz-Gatti 2000, Petean 2002, 2009, Breier 2005, Kersten 2006, Kersten \& Silva 2006, Mancinelli \& Esemann-Quadros 2007) e em cinco países da América Tropical (Gentry \& Dodson 1987a, Ingram et al. 1996, Ibisch 1996, Engwald 1999, Benavides et al. 2005).

Para a comparação da florística de epífitas vasculares, registrada em diferentes altitudes da área de estudo e em outros trabalhos realizados no sul e sudeste do Brasil, construiu-se uma matriz de similaridade florística com base no índice de Jaccard (Mueller-Dombois \& Ellenberg 1974). Foram escolhidos trabalhos que abrangeram epífitas vasculares em trechos de Floresta Ombrófila Densa de encosta (Schütz-Gatti 2000, Petean 2002, 2009, Breier 2005). Para enriquecer as comparações foram também incluídos um trabalho realizado em Floresta Ombrófila Densa de planície litorânea (Kersten \& Silva 2005) e outro em área de transição entre a Floresta Ombrófila Densa e a Floresta Ombrófila Mista (Kersten 2006, Kersten \& Kuniyoshi 2006), ambos por se encontrarem relativamente próximos da área de estudo. Foram apenas considerados os taxa determinados em nível de espécie.

\section{Resultados}

Foram registradas 278 espécies de epífitas vasculares distribuídas em 109 gêneros e 30 famílias. As pteridófitas foram representadas 
Blum, C.T. et al.
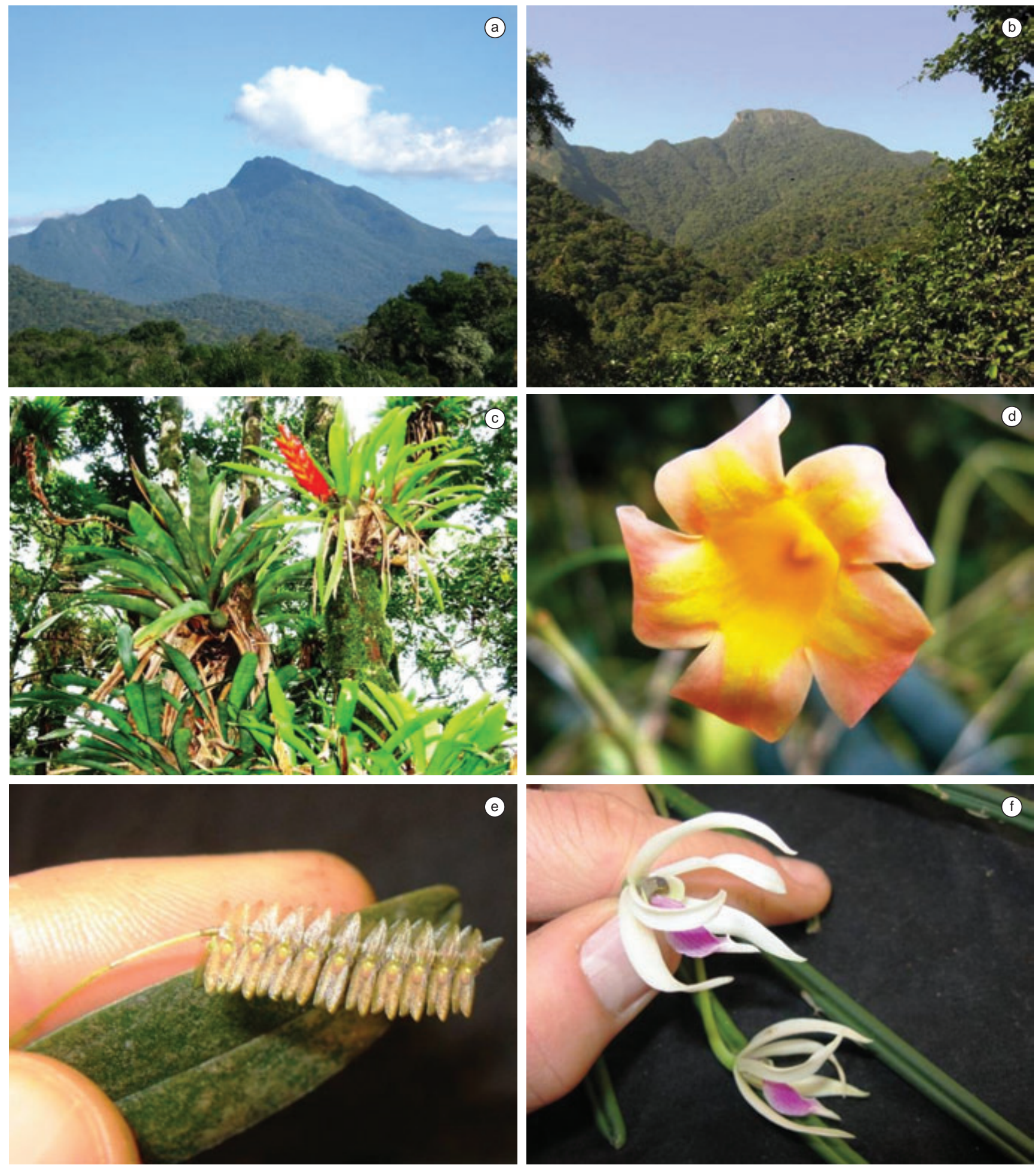

Figura 2. a) Face norte da Torre da Prata, ponto culminante da Serra da Prata, Paraná; b) Torre da Prata, vista tomada aos 400 m s.n.m.; c) Vriesea platynema (esquerda) e Vriesea incurvata (direita), holoepífitas aos 800 m s.n.m.; d) Mandevilla urophylla, hemiepífita aos 600 m s.n.m.; e) Lepanthopsis floripecten, vulnerável no Paraná; f) Leptotes bicolor, em perigo no Paraná.

Figure 2. a) North face of the Prata Tower, highest peak of the Prata Mountain Range, in Paraná State; b) Prata Tower, view from $400 \mathrm{~m}$ a.s.1.; c) Vriesea platynema (left) and Vriesea incurvata (right), holoepiphytes at $800 \mathrm{~m}$ a.s.1.; d) Mandevilla urophylla, hemiepiphyte at $600 \mathrm{~m}$ a.s.1.; e) Lepanthopsis floripecten, vulnerable in Paraná State; f) Leptotes bicolor, endangered in Paraná State.

por 74 espécies de 30 gêneros e 10 famílias (Tabela 1), das quais 66 monilófitas e oito licófitas. As angiospermas foram representadas por 204 espécies, sendo 14 magnoliídeas (um gênero e uma família), 156 monocotiledôneas (56 gêneros e quatro famílias) e 34 eudicotiledôneas (22 gêneros e 15 famílias). Deste total, 270 espécies foram registradas em campo pelo autor, sendo as oito restantes referentes a coletas realizadas no mesmo local durante o estudo de Paciencia (2008) e que foram tombadas no Herbário UPCB. 
Tabela 1. Espécies de epífitas vasculares registradas em Floresta Ombrófila Densa na Serra da Prata, Morretes, PR.

Table 1. Vascular epiphytes species of Atlantic Rainforest in the Prata Mountain Range, Morretes, Paraná State.

\begin{tabular}{|c|c|c|c|c|c|c|}
\hline \multirow{2}{*}{$\begin{array}{c}\text { Família (no.-\% de espécies) } \\
\text { Espécie }\end{array}$} & \multirow[t]{2}{*}{ Categ. } & \multicolumn{4}{|c|}{ Faixa altitudinal (m) } & \multirow[t]{2}{*}{ Registro } \\
\hline & & $\begin{array}{l}400 \\
500\end{array}$ & $\begin{array}{l}600 \\
700\end{array}$ & $\begin{array}{l}800 \\
900\end{array}$ & 1000 & \\
\hline \multicolumn{7}{|l|}{ AMARYLLIDACEAE $(1-0,4 \%)$} \\
\hline Hippeastrum aulicum (Ker Gawl.) Herb. & HLF & - & $\mathrm{X}$ & $\mathrm{X}$ & $\mathrm{X}$ & 09-044 \\
\hline \multicolumn{7}{|l|}{ APOCYNACEAE $(3-1,1 \%)$} \\
\hline Mandevilla atroviolacea (Stadelm.) Woodson & HMP & $\mathrm{X}$ & $\mathrm{X}$ & $\mathrm{X}$ & - & $08-251$ \\
\hline Mandevilla immaculata Woodson & HMP & - & - & $\mathrm{X}$ & $\mathrm{X}$ & В05CM20 \\
\hline Mandevilla urophylla (Hook.) Woodson & HMP & $\mathrm{X}$ & $\mathrm{X}$ & - & - & F14CM17 \\
\hline \multicolumn{7}{|l|}{ ARACEAE $(14-5,1 \%)$} \\
\hline Anthurium acutum N.E. Br. & HLA & - & - & $\mathrm{X}$ & $\mathrm{X}$ & 08-088 \\
\hline Anthurium gaudichaudianum Kunth & HLP & $\mathrm{X}$ & $\mathrm{X}$ & $\mathrm{X}$ & $\mathrm{X}$ & 08-027 \\
\hline Anthurium longifolium (Hoffm.) G. Don & HLP & $\mathrm{X}$ & $\mathrm{X}$ & $\mathrm{X}$ & - & H1CM05 \\
\hline Anthurium pentaphyllum (Aubl.) G. Don & HMS & $\mathrm{X}$ & - & $\mathrm{X}$ & - & D26FB01 \\
\hline Anthurium scandens (Aubl.) Engl. & HLO & $\mathrm{X}$ & $X$ & $\mathrm{X}$ & - & $08-123$ \\
\hline Anthurium sellowianum Kunth & HLP & $\mathrm{X}$ & $\mathrm{X}$ & $\mathrm{X}$ & $\mathrm{X}$ & 08-039 \\
\hline Heteropsis rigidifolia Engl. & HMS & $\mathrm{X}$ & $\mathrm{X}$ & - & - & es,im \\
\hline Monstera adansonii Schott & HMS & $\mathrm{X}$ & - & - & - & 09-021 \\
\hline Philodendron appendiculatum Nadruz \& Mayo & HMP & $\mathrm{X}$ & $\mathrm{X}$ & $\mathrm{X}$ & $\mathrm{X}$ & $09-222$ \\
\hline Philodendron corcovadense Kunth & HMP & $\mathrm{X}$ & $\mathrm{X}$ & - & - & $09-228$ \\
\hline Philodendron crassinervium Lindl. & HMS & $\mathrm{X}$ & $\mathrm{X}$ & $\mathrm{X}$ & - & es,im \\
\hline Philodendron loefgrenii Engl. & HMP & $\mathrm{X}$ & $\mathrm{X}$ & $\mathrm{X}$ & $\mathrm{X}$ & $09-167$ \\
\hline Philodendron obliquifolium Engl. & HMS & $\mathrm{X}$ & - & - & - & $09-232$ \\
\hline Philodendron propinquum Schott & HMS & $\mathrm{X}$ & $\mathrm{X}$ & $\mathrm{X}$ & $\mathrm{X}$ & F03FM01 \\
\hline \multicolumn{7}{|l|}{ ARALIACEAE $(1-0,4 \%)$} \\
\hline Dendropanax cuneatus (DC.) Decne. \& Planch. & HMP & $\mathrm{X}$ & $\mathrm{X}$ & - & - & 08-179 \\
\hline \multicolumn{7}{|l|}{ BEGONIACEAE $(3-1,1 \%)$} \\
\hline Begonia fruticosa A. DC. & HMS & $\mathrm{X}$ & $\mathrm{X}$ & - & $\mathrm{X}$ & F22FM02 \\
\hline Begonia paleata Schott ex A. DC. & HLA & - & - & - & $X$ & 08-085 \\
\hline Begonia radicans Vell. & HMS & $\mathrm{X}$ & - & $\mathrm{X}$ & $\mathrm{X}$ & $08-058$ \\
\hline \multicolumn{7}{|l|}{ BROMELIACEAE $(38-13,4 \%)$} \\
\hline Aechmea coelestis (K. Koch) E. Morren & HLP & - & $\mathrm{X}$ & $\mathrm{X}$ & $\mathrm{X}$ & $08-031$ \\
\hline Aechmea cylindrata Lindm. & HLP & $\mathrm{X}$ & $\mathrm{X}$ & $\mathrm{X}$ & $X$ & $09-180$ \\
\hline Aechmea nudicaulis (L.) Griseb. & HLP & $\mathrm{X}$ & $X$ & $\mathrm{X}$ & - & es,im \\
\hline Aechmea organensis Wawra & HLP & $\mathrm{X}$ & $\mathrm{X}$ & $\mathrm{X}$ & - & 09-094 \\
\hline Aechmea ornata Baker & HLP & $\mathrm{X}$ & $X$ & $\mathrm{X}$ & $X$ & es,im \\
\hline Billbergia amoena (Lodd.) Lindl. & HLP & $\mathrm{X}$ & - & - & - & 09-085 \\
\hline Canistrum lindenii (Regel) Mez & HLO & $\mathrm{X}$ & $X$ & $\mathrm{X}$ & - & $\mathrm{im}$ \\
\hline Neoregelia laevis (Mez) L.B. Sm. & HLO & $\mathrm{X}$ & $\mathrm{X}$ & - & - & $10-002$ \\
\hline Nidularium amazonicum (Baker) Lindm. \& E. Morren & HLF & $\mathrm{X}$ & $\mathrm{X}$ & $\mathrm{X}$ & - & 09-081 \\
\hline Nidularium campo-alegrensis Leme & HLF & - & - & - & $\mathrm{X}$ & es,im \\
\hline Nidularium innocentii Lem. & HLF & $\mathrm{X}$ & $X$ & $\mathrm{X}$ & $\mathrm{X}$ & $10-001$ \\
\hline
\end{tabular}

Categorias ecológicas (Categ.: HLO-holoepífito obrigatório, HLP-holoepífito preferencial, HLF-holoepífito facultativo, HLA-holoepífito acidental, HMP-hemiepífito primário, HMS-hemiepífito secundário). Números de coleta do primeiro autor, exceto aqueles com iniciais de outros coletores

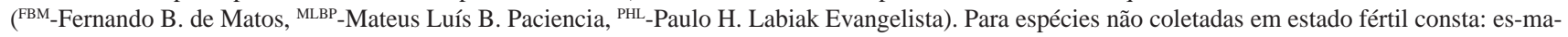
terial vegetativo, im-imagem digital, vi-material vivo em cultivo. De acordo com SEMA (Paraná 1995), constam categorias de espécies ameaçadas: *rara; **vulnerável; ***em perigo.

Ecological categories (Categ.: HLO-obligatory holoepiphyte, HLP-preferential holoepiphyte, HLF-facultative holoepiphyte, HLA-accidental holoepiphyte, HMP-primary hemiepiphyte, HMS-secondary holoepiphyte). Collect numbers of the first author, except those with abreviations of other collectors (FBM-Fernando B. de Matos, MLBP-Mateus Luís B. Paciencia, PHL-Paulo H. Labiak Evangelista). For species not collected in fertile state: es-vegetative material, im-digital image, vi-live material in cultive. According SEMA (Paraná 1995), are indicated the status of threatened species: *rare; **vulnerable; ***endangered. 
Tabela 1. Continuação...

\begin{tabular}{|c|c|c|c|c|c|c|}
\hline \multirow{2}{*}{$\begin{array}{c}\text { Família (no.-\% de espécies) } \\
\text { Espécie }\end{array}$} & \multirow[t]{2}{*}{ Categ. } & \multicolumn{4}{|c|}{ Faixa altitudinal (m) } & \multirow[t]{2}{*}{ Registro } \\
\hline & & $\begin{array}{l}400 \\
500\end{array}$ & $\begin{array}{l}600 \\
700\end{array}$ & $\begin{array}{l}800 \\
900\end{array}$ & $\begin{array}{l}1000 \\
1100\end{array}$ & \\
\hline Nidularium procerum Lindm. & HLP & $\mathrm{X}$ & $\mathrm{X}$ & $\mathrm{X}$ & $\mathrm{X}$ & H03FM27 \\
\hline Racinaea spiculosa (Griseb.) M.A. Spencer \& L.B. Sm. ** & HLO & $\mathrm{X}$ & - & - & - & 08-018 \\
\hline Tillandsia geminiflora Brongn. & HLO & $\mathrm{X}$ & $\mathrm{X}$ & $X$ & $\mathrm{X}$ & 08-001 \\
\hline Tillandsia linearis Vell. & HLO & $\mathrm{X}$ & - & - & - & es \\
\hline Tillandsia stricta Sol. ex Sims & HLO & $\mathrm{X}$ & $\mathrm{X}$ & $\mathrm{X}$ & $X$ & D24CM01 \\
\hline Tillandsia tenuifolia $\mathrm{L}$. & HLO & $X$ & $\mathrm{X}$ & $X$ & $X$ & H30СE09 \\
\hline Tillandsia usneoides (L.) L. & HLO & $\mathrm{X}$ & - & - & - & im \\
\hline Vriesea altodaserrae L.B. Sm. & HLP & - & - & $\mathrm{X}$ & $\mathrm{X}$ & $10-016$ \\
\hline Vriesea carinata Wawra & HLO & $X$ & $\mathrm{X}$ & $X$ & - & $09-245$ \\
\hline Vriesea ensiformis (Vell.) Beer & HLP & $X$ & - & - & - & 09-007 \\
\hline Vriesea erythrodactylon (E. Morren) E. Morren ex Mez & HLP & $\mathrm{X}$ & $\mathrm{X}$ & $\mathrm{X}$ & - & $09-172$ \\
\hline Vriesea flammea L.B. Sm. & HLO & $X$ & $\mathrm{X}$ & $\mathrm{X}$ & $\mathrm{X}$ & es,im \\
\hline Vriesea flava A. F. Costa, H. Luther \& Wand. & HLP & $\mathrm{X}$ & $\mathrm{X}$ & $\mathrm{X}$ & $\mathrm{X}$ & 08-019 \\
\hline Vriesea gigantea Gaudich. & HLP & $\mathrm{X}$ & $\mathrm{X}$ & - & - & es,im \\
\hline Vriesea guttata Linden \& André & HLP & - & $\mathrm{X}$ & $\mathrm{X}$ & $\mathrm{X}$ & $\mathrm{im}$ \\
\hline Vriesea heterostachys (Baker) L.B. Sm. & HLP & - & - & $\mathrm{X}$ & $\mathrm{X}$ & 09-182 \\
\hline Vriesea incurvata Gaudich. & HLP & $\mathrm{X}$ & $\mathrm{X}$ & $\mathrm{X}$ & - & 09-219 \\
\hline Vriesea paratiensis E. Pereira & HLP & $\mathrm{X}$ & $\mathrm{X}$ & - & - & es,im \\
\hline Vriesea philippocoburgii Wawra & HLP & $\mathrm{X}$ & $\mathrm{X}$ & $\mathrm{X}$ & - & $\mathrm{im}$ \\
\hline Vriesea platynema Gaudich. & HLP & - & - & $\mathrm{X}$ & $\mathrm{X}$ & es,im \\
\hline Vriesea aff. tijucana E. Pereira & HLP & $X$ & $\mathrm{X}$ & $\mathrm{X}$ & - & $10-017$ \\
\hline Vriesea vagans (L.B. Sm.) L.B. Sm. & HLO & $X$ & $\mathrm{X}$ & $\mathrm{X}$ & $\mathrm{X}$ & $10-003$ \\
\hline Vriesea sp.1 & HLP & - & $\mathrm{X}$ & $\mathrm{X}$ & $\mathrm{X}$ & es,im \\
\hline Vriesea sp.2 & HLP & - & - & $\mathrm{X}$ & - & 09-018 \\
\hline Vriesea sp.3 & HLP & - & - & $\mathrm{X}$ & - & $11-049$ \\
\hline Wittrockia cyathiformis (Vell.) Leme & HLP & - & $\mathrm{X}$ & - & - & es \\
\hline Wittrockia superba Lindm. & HLP & $\mathrm{X}$ & $\mathrm{X}$ & - & - & es,im \\
\hline \multicolumn{7}{|l|}{ CACTACEAE $(9-3,2 \%)$} \\
\hline Hatiora gaertneri (Regel) Barthlott & HLO & - & - & $\mathrm{X}$ & $\mathrm{X}$ & $\mathrm{im}$ \\
\hline Lepismium houlletianum (Lem.) Barthlott & HLO & $\mathrm{X}$ & $\mathrm{X}$ & $\mathrm{X}$ & $X$ & $08-055$ \\
\hline Rhipsalis cf. burchellii Britton \& Rose & HLO & $\mathrm{X}$ & $\mathrm{X}$ & $\mathrm{X}$ & - & F18CI31 \\
\hline Rhipsalis campos-portoana Loefgr. & HLO & $\mathrm{X}$ & $\mathrm{X}$ & - & $\mathrm{X}$ & F04CI09 \\
\hline Rhipsalis elliptica G. Lindb. ex K. Schum. & HLO & $\mathrm{X}$ & $\mathrm{X}$ & $\mathrm{X}$ & - & 09-076 \\
\hline Rhipsalis floccosa Salm-Dyck ex Pfeiff. & HLO & $X$ & - & $\mathrm{X}$ & $X$ & D23FM06 \\
\hline Rhipsalis pachyptera Pfeiff. & HLO & $\mathrm{X}$ & $\mathrm{X}$ & $\mathrm{X}$ & - & D21FM24 \\
\hline Rhipsalis teres (Vell.) Steud. & HLO & $X$ & $\mathrm{X}$ & $X$ & $\mathrm{X}$ & H18FM08 \\
\hline Rhipsalis trigona Pfeiff. & HLO & $X$ & - & - & - & es \\
\hline \multicolumn{7}{|l|}{ CLUSIACEAE $(1-0,4 \%)$} \\
\hline Clusia criuva Cambess. & HMP & $\mathrm{X}$ & $\mathrm{X}$ & $X$ & $\mathrm{X}$ & es,im \\
\hline
\end{tabular}

Categorias ecológicas (Categ.: HLO-holoepífito obrigatório, HLP-holoepífito preferencial, HLF-holoepífito facultativo, HLA-holoepífito acidental, HMP-hemiepífito primário, HMS-hemiepífito secundário). Números de coleta do primeiro autor, exceto aqueles com iniciais de outros coletores

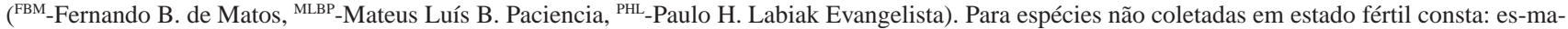
terial vegetativo, im-imagem digital, vi-material vivo em cultivo. De acordo com SEMA (Paraná 1995), constam categorias de espécies ameaçadas: *rara; **vulnerável; ***em perigo.

Ecological categories (Categ.: HLO-obligatory holoepiphyte, HLP-preferential holoepiphyte, HLF-facultative holoepiphyte, HLA-accidental holoepiphyte, HMP-primary hemiepiphyte, HMS-secondary holoepiphyte). Collect numbers of the first author, except those with abreviations of other collectors (FBM-Fernando B. de Matos, MLBP-Mateus Luís B. Paciencia, PHL-Paulo H. Labiak Evangelista). For species not collected in fertile state: es-vegetative material, im-digital image, vi-live material in cultive. According SEMA (Paraná 1995), are indicated the status of threatened species: *rare; **vulnerable; ***endangered. 
Tabela 1. Continuação...

\begin{tabular}{|c|c|c|c|c|c|c|}
\hline \multirow{2}{*}{$\begin{array}{c}\text { Família (no.-\% de espécies) } \\
\text { Espécie }\end{array}$} & \multirow[t]{2}{*}{ Categ. } & \multicolumn{4}{|c|}{ Faixa altitudinal (m) } & \multirow[t]{2}{*}{ Registro } \\
\hline & & $\begin{array}{l}400 \\
500\end{array}$ & $\begin{array}{l}600 \\
700\end{array}$ & $\begin{array}{l}800 \\
900\end{array}$ & 1000 & \\
\hline \multicolumn{7}{|l|}{ GENTIANACEAE $(1-0,4 \%)$} \\
\hline Voyria aphylla (Jacq.) Pers. * & HLA & $\mathrm{X}$ & - & - & - & H07CE06 \\
\hline \multicolumn{7}{|l|}{ GESNERIACEAE $(5-1,8 \%)$} \\
\hline Codonanthe devosiana Lem. & HLP & $\mathrm{X}$ & $\mathrm{X}$ & $\mathrm{X}$ & - & $08-122$ \\
\hline Codonanthe gracilis (Mart.) Hanst. & HLP & $\mathrm{X}$ & $\mathrm{X}$ & - & - & F18CI01 \\
\hline Nematanthus australis Chautems & HLP & - & - & $X$ & $X$ & $08-073$ \\
\hline Nematanthus tessmannii (Hoehne) Chautems & HLP & $\mathrm{X}$ & $\mathrm{X}$ & $\mathrm{X}$ & $\mathrm{X}$ & 08-072 \\
\hline Sinningia douglasii (Lindl.) Chautems & HLP & $\mathrm{X}$ & $\mathrm{X}$ & $\mathrm{X}$ & - & $09-157$ \\
\hline \multicolumn{7}{|l|}{ GRISELINIACEAE $(1-0,4 \%)$} \\
\hline Griselinia ruscifolia (Clos) Taub. & HMP & - & - & - & $\mathrm{X}$ & es \\
\hline \multicolumn{7}{|l|}{ MALVACEAE $(1-0,4 \%)$} \\
\hline Spirotheca passifloroides Cuatrec. & HMP & $\mathrm{X}$ & $\mathrm{X}$ & $\mathrm{X}$ & - & $\mathrm{im}$ \\
\hline \multicolumn{7}{|l|}{ MELASTOMATACEAE $(3-1,1 \%)$} \\
\hline Bertolonia mosenii Cogn. & HLA & $X$ & - & - & - & $08-112$ \\
\hline Clidemia blepharodes DC. & HLO & $\mathrm{X}$ & $\mathrm{X}$ & $\mathrm{X}$ & - & 09-209 \\
\hline Pleiochiton ebracteatum Triana & HLO & $\mathrm{X}$ & $\mathrm{X}$ & $\mathrm{X}$ & $\mathrm{X}$ & D04CI17 \\
\hline \multicolumn{7}{|l|}{ MORACEAE $(1-0,4 \%)$} \\
\hline Ficus enormis (Mart. ex Miq.) Mart. & HMP & $\mathrm{X}$ & $\mathrm{X}$ & $\mathrm{X}$ & $\mathrm{X}$ & es \\
\hline \multicolumn{7}{|l|}{ ONAGRACEAE $(1-0,4 \%)$} \\
\hline Fuchsia regia (Vell.) Munz & HMP & $\mathrm{X}$ & $X$ & - & $X$ & $\mathrm{im}$ \\
\hline \multicolumn{7}{|l|}{ ORCHIDACEAE $(103-37,2 \%)$} \\
\hline Acianthera auriculata (Lindl.) Pridgeon \& M.W.Chase & HLO & $X$ & $\mathrm{X}$ & - & - & 08-196 \\
\hline Acianthera glanduligera (Lindl.) Luer & HLO & $\mathrm{X}$ & $\mathrm{X}$ & - & - & F03CI24 \\
\hline Acianthera oligantha (Barb.Rodr.) F.Barros & HLO & $\mathrm{X}$ & - & - & - & H19CI29 \\
\hline Acianthera saundersiana (Rchb.f.) Pridgeon \& M.W.Chase & HLO & $\mathrm{X}$ & - & - & $\mathrm{X}$ & B28FM10 \\
\hline Anathallis heterophylla Barb.Rodr. & HLO & - & - & $\mathrm{X}$ & - & D05FA05 \\
\hline Anathallis obovata (Lindl.) Pridgeon \& M.W.Chase * & HLO & - & $\mathrm{X}$ & $\mathrm{X}$ & - & D06FM12 \\
\hline Anathallis rubens (Lindl.) Pridgeon \& M.W.Chase & HLO & $\mathrm{X}$ & $\mathrm{X}$ & $\mathrm{X}$ & $\mathrm{X}$ & $08-229$ \\
\hline Barbosella gardneri (Lindl.) Schltr. & HLO & $\mathrm{X}$ & - & - & - & $09-115$ \\
\hline Bifrenaria aureofulva Lindl. & HLO & - & - & $\mathrm{X}$ & - & $08-240$ \\
\hline Bifrenaria harrisoniae (Hook.) Rchb.f. & HLO & - & - & $\mathrm{X}$ & $\mathrm{X}$ & $08-140$ \\
\hline Bulbophyllum glutinosum (Barb.Rodr.) Cogn. & HLO & $\mathrm{X}$ & - & - & - & H02FA05 \\
\hline Bulbophyllum granulosum Barb.Rodr. & HLO & $X$ & $X$ & $\mathrm{X}$ & $\mathrm{X}$ & $08-157$ \\
\hline Bulbophyllum napellii Lindl. & HLO & - & $\mathrm{X}$ & $\mathrm{X}$ & - & 09-194 \\
\hline Campylocentrum sellowii (Rchb.f.) Rolfe & HLO & $\mathrm{X}$ & $\mathrm{X}$ & - & - & H17CM14 \\
\hline Campylocentrum ulaei Cogn. & HLO & $\mathrm{X}$ & $\mathrm{X}$ & - & - & 08-199 \\
\hline Cattleya forbesii Lindl. & HLO & $\mathrm{X}$ & - & - & - & es \\
\hline Cirrhaea dependens Loudon & HLO & $\mathrm{X}$ & $\mathrm{X}$ & - & - & F17CI18 \\
\hline Dichaea pendula Cogn. & HLP & $X$ & - & - & - & H13CI28 \\
\hline Dichaea cogniauxiana Schltr. & HLO & $\mathrm{X}$ & $\mathrm{X}$ & $\mathrm{X}$ & $\mathrm{X}$ & $09-067$ \\
\hline Dryadella zebrina (Porsch) Luer & HLO & - & $X$ & $X$ & $\mathrm{X}$ & $08-231$ \\
\hline Elleanthus brasiliensis (Lindl.) Rchb.f. & HLO & $X$ & - & $\mathrm{X}$ & - & 09-009 \\
\hline
\end{tabular}

Categorias ecológicas (Categ.: HLO-holoepífito obrigatório, HLP-holoepífito preferencial, HLF-holoepífito facultativo, HLA-holoepífito acidental, HMP-hemiepífito primário, HMS-hemiepífito secundário). Números de coleta do primeiro autor, exceto aqueles com iniciais de outros coletores ( ${ }^{\mathrm{FBM}}$-Fernando B. de Matos, ${ }^{\mathrm{MLBP}}$-Mateus Luís B. Paciencia, ${ }^{\mathrm{PHL}}$-Paulo H. Labiak Evangelista). Para espécies não coletadas em estado fértil consta: es-material vegetativo, im-imagem digital, vi-material vivo em cultivo. De acordo com SEMA (Paraná 1995), constam categorias de espécies ameaçadas: *rara; **vulnerável; ***em perigo.

Ecological categories (Categ.: HLO-obligatory holoepiphyte, HLP-preferential holoepiphyte, HLF-facultative holoepiphyte, HLA-accidental holoepiphyte, HMP-primary hemiepiphyte, HMS-secondary holoepiphyte). Collect numbers of the first author, except those with abreviations of other collectors (FBM-Fernando B. de Matos, MLBP-Mateus Luís B. Paciencia, PHL-Paulo H. Labiak Evangelista). For species not collected in fertile state: es-vegetative material, im-digital image, vi-live material in cultive. According SEMA (Paraná 1995), are indicated the status of threatened species: *rare; **vulnerable; ***endangered. 
Tabela 1. Continuação...

\begin{tabular}{|c|c|c|c|c|c|c|}
\hline \multirow{2}{*}{$\begin{array}{c}\text { Família (no.-\% de espécies) } \\
\text { Espécie }\end{array}$} & \multirow[t]{2}{*}{ Categ. } & \multicolumn{4}{|c|}{ Faixa altitudinal (m) } & \multirow[t]{2}{*}{ Registro } \\
\hline & & $\begin{array}{l}400 \\
500\end{array}$ & $\begin{array}{l}600 \\
700\end{array}$ & $\begin{array}{l}800 \\
900\end{array}$ & $\begin{array}{l}1000 \\
1100\end{array}$ & \\
\hline Encyclia oncidioides (Lindl.) Schltr. & HLO & $\mathrm{X}$ & $\mathrm{X}$ & $\mathrm{X}$ & - & D01CE17 \\
\hline Epidendrum addae Pabst & HLO & - & - & $\mathrm{X}$ & - & $08-245$ \\
\hline Epidendrum pseudodiforme Hoehne \& Schlechter & HLO & - & - & $\mathrm{X}$ & - & D6CE07 \\
\hline Epidendrum armeniacum Lindl. & HLO & $\mathrm{X}$ & $\mathrm{X}$ & $\mathrm{X}$ & - & $08-044$ \\
\hline Epidendrum densiflorum Hook. & HLO & $\mathrm{X}$ & $\mathrm{X}$ & $\mathrm{X}$ & - & F22CM04 \\
\hline Epidendrum latilabre Lindl. & HLO & $\mathrm{X}$ & $X$ & - & - & es \\
\hline Epidendrum paranaense Barb.Rodr. & HLO & $\mathrm{X}$ & $\mathrm{X}$ & - & - & F24CM19 \\
\hline Epidendrum proligerum Barb.Rodr. & HLO & $\mathrm{X}$ & $\mathrm{X}$ & $\mathrm{X}$ & $\mathrm{X}$ & 09-096 \\
\hline Epidendrum ramosum Jacq. & HLO & $\mathrm{X}$ & - & $\mathrm{X}$ & - & H04CM11 \\
\hline Epidendrum secundum Jacq. & HLO & - & $\mathrm{X}$ & $\mathrm{X}$ & - & F03CE21 \\
\hline Epidendrum strobiliferum Rchb.f. & HLO & $\mathrm{X}$ & $\mathrm{X}$ & - & - & H30CE24 \\
\hline Epidendrum tridactylum Lindl. & HLO & $\mathrm{X}$ & - & - & - & H26CI23 \\
\hline Epidendrum sp.1 & HLO & $\mathrm{X}$ & - & - & - & vi \\
\hline Eurystyles lorenzii (Cogn.) Schltr. ** & HLO & $\mathrm{X}$ & $\mathrm{X}$ & - & - & $08-220$ \\
\hline Gomesa crispa (Lindl.) Klotzsch ex Rchb.f. & HLO & - & $\mathrm{X}$ & $\mathrm{X}$ & - & $09-100$ \\
\hline Gomesa glaziovii Cogn. & HLO & - & - & $\mathrm{X}$ & $\mathrm{X}$ & $08-236$ \\
\hline Gomesa recurva $\mathrm{R} . \mathrm{Br}$. & HLO & - & $\mathrm{X}$ & - & $\mathrm{X}$ & $08-214$ \\
\hline Grobya galeata Lindl. & HLO & - & - & - & $\mathrm{X}$ & 09-048 \\
\hline Heterotaxis brasiliensis (Brieger \& Illg) F.Barros & HLO & $\mathrm{X}$ & $\mathrm{X}$ & $\mathrm{X}$ & - & 08-198 \\
\hline Isochilus linearis (Jacq.) R.Br. & HLO & $\mathrm{X}$ & $\mathrm{X}$ & $\mathrm{X}$ & - & 08-195 \\
\hline Lankesterella ceracifolia (Barb.Rodr.) Mansf. & HLO & $\mathrm{X}$ & $\mathrm{X}$ & $\mathrm{X}$ & $\mathrm{X}$ & 08-145 \\
\hline Lepanthopsis floripecten (Rchb.f.) Ames ** & HLO & $\mathrm{X}$ & - & - & - & H01CM09 \\
\hline Leptotes bicolor Lindl. *** & HLO & $X$ & - & - & - & H02CM03 \\
\hline Lockhartia lunifera Rchb. f. & HLO & $\mathrm{X}$ & - & - & - & vi \\
\hline Malaxis excavata (Lindl.) Kuntze & HLF & - & $\mathrm{X}$ & - & - & F06CM06 \\
\hline Maxillaria murilliana Hoehne & HLO & $\mathrm{X}$ & $\mathrm{X}$ & - & - & $08-250$ \\
\hline Maxillaria cleistogama Brieger \& Illg & HLO & $\mathrm{X}$ & - & - & - & H02FA06 \\
\hline Maxillaria cogniauxiana Hoehne & HLO & - & - & $\mathrm{X}$ & - & D22FM02 \\
\hline Maxillaria imbricata Barb.Rodr. & HLO & $\mathrm{X}$ & - & $\mathrm{X}$ & - & H11CE17 \\
\hline Maxillaria mosenii Kraenzl. & HLO & - & - & $\mathrm{X}$ & - & D22FM11 \\
\hline Maxillaria notylioglossa Rchb.f. & HLO & - & - & $\mathrm{X}$ & - & $08-228$ \\
\hline Maxillaria ochroleuca Lodd. ex Lindl. & HLO & $\mathrm{X}$ & - & $\mathrm{X}$ & - & $09-124$ \\
\hline Maxillaria picta Hook. & HLO & $\mathrm{X}$ & $\mathrm{X}$ & $\mathrm{X}$ & $\mathrm{X}$ & 09-118 \\
\hline Maxillaria rigida Barb.Rodr. & HLO & - & - & $\mathrm{X}$ & - & D20CE19 \\
\hline Maxillaria rufescens Lindl. & HLO & - & $\mathrm{X}$ & - & - & F14CI20 \\
\hline Maxillaria sp.1 & HLO & $X$ & $\mathrm{X}$ & - & - & $08-221$ \\
\hline Miltonia regnellii Rchb.f. & HLO & $\mathrm{X}$ & $\mathrm{X}$ & - & - & H09CM29 \\
\hline Octomeria grandiflora Lindl. & HLO & $\mathrm{X}$ & - & - & - & vi \\
\hline Octomeria albopurpurea Barb.Rodr. & HLO & $\mathrm{X}$ & $\mathrm{X}$ & - & - & F29FM10 \\
\hline Octomeria fibrifera Schltr. & HLO & $\mathrm{X}$ & - & $\mathrm{X}$ & $\mathrm{X}$ & 09-028 \\
\hline Octomeria gracilis Lodd. ex Lindl. & HLO & $\mathrm{X}$ & - & $\mathrm{X}$ & $\mathrm{X}$ & 08-008 \\
\hline Octomeria juncifolia Barb.Rodr. & HLO & $\mathrm{X}$ & $\mathrm{X}$ & - & - & 08-194 \\
\hline
\end{tabular}

Categorias ecológicas (Categ.: HLO-holoepífito obrigatório, HLP-holoepífito preferencial, HLF-holoepífito facultativo, HLA-holoepífito acidental, HMP-hemiepífito primário, HMS-hemiepífito secundário). Números de coleta do primeiro autor, exceto aqueles com iniciais de outros coletores

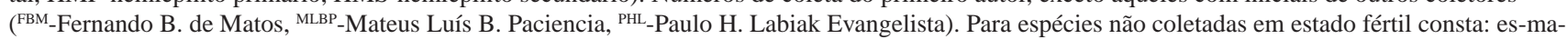
terial vegetativo, im-imagem digital, vi-material vivo em cultivo. De acordo com SEMA (Paraná 1995), constam categorias de espécies ameaçadas: *rara; **vulnerável; ***em perigo.

Ecological categories (Categ.: HLO-obligatory holoepiphyte, HLP-preferential holoepiphyte, HLF-facultative holoepiphyte, HLA-accidental holoepiphyte, HMP-primary hemiepiphyte, HMS-secondary holoepiphyte). Collect numbers of the first author, except those with abreviations of other collectors (FBM-Fernando B. de Matos, MLBP-Mateus Luís B. Paciencia, PHL-Paulo H. Labiak Evangelista). For species not collected in fertile state: es-vegetative material, im-digital image, vi-live material in cultive. According SEMA (Paraná 1995), are indicated the status of threatened species: *rare; **vulnerable; ***endangered. 
Tabela 1. Continuação...

\begin{tabular}{|c|c|c|c|c|c|c|}
\hline \multirow{3}{*}{$\begin{array}{c}\text { Família (no.-\% de espécies) } \\
\text { Espécie }\end{array}$} & \multirow[t]{3}{*}{ Categ. } & \multicolumn{4}{|c|}{ Faixa altitudinal (m) } & \multirow[t]{3}{*}{ Registro } \\
\hline & & 400 & 600 & 800 & 1000 & \\
\hline & & 500 & 700 & 900 & 1100 & \\
\hline Octomeria sp.1 & HLO & $\mathrm{X}$ & $\mathrm{X}$ & $\mathrm{X}$ & $\mathrm{X}$ & D04CE05 \\
\hline Oncidium divaricatum Lindl. & HLO & $\mathrm{X}$ & $\mathrm{X}$ & - & $X$ & $08-136$ \\
\hline Oncidium fimbriatum Lindl. & HLO & $\mathrm{X}$ & - & - & - & $08-252$ \\
\hline Oncidium flexuosum Lodd. & HLO & $\mathrm{X}$ & - & - & - & H07CE26 \\
\hline Oncidium gardneri Lindl. & HLO & $\mathrm{X}$ & $\mathrm{X}$ & - & $\mathrm{X}$ & F19CI31 \\
\hline Oncidium hookeri Rolfe & HLO & - & - & $X$ & - & 09-015 \\
\hline Oncidium longipes Lindl. & HLO & $\mathrm{X}$ & $\mathrm{X}$ & $X$ & $\mathrm{X}$ & 08-172 \\
\hline Oncidium pubes Lindl. & HLO & $\mathrm{X}$ & $\mathrm{X}$ & - & - & $08-165$ \\
\hline Panmorphia sp.1 & HLO & $\mathrm{X}$ & - & $\mathrm{X}$ & $\mathrm{X}$ & D04CE12 \\
\hline Phymatidium falcifolium Lindl. & HLO & $\mathrm{X}$ & - & - & - & H09CM12 \\
\hline Pleurothallis fusca Lindl. & HLO & $\mathrm{X}$ & $\mathrm{X}$ & $\mathrm{X}$ & $\mathrm{X}$ & 08-037 \\
\hline Pleurothallis parviflora Luer & HLO & $\mathrm{X}$ & - & $X$ & $\mathrm{X}$ & 09-047 \\
\hline Pleurothallis pleurothalloides (Cogn.) Handro & HLO & $\mathrm{X}$ & $\mathrm{X}$ & $\mathrm{X}$ & - & $08-232$ \\
\hline Pleurothallis sp.1 & HLO & $X$ & - & $\mathrm{X}$ & $X$ & B13FM14 \\
\hline Pleurothallis sp. 2 & HLO & - & $\mathrm{X}$ & $\mathrm{X}$ & - & $09-193$ \\
\hline Pleurothallis sp.3 & HLO & - & - & $\mathrm{X}$ & - & vi \\
\hline Pleurothallis sp.4 & HLO & - & - & $\mathrm{X}$ & - & $08-226$ \\
\hline Polystachya concreta (Jacq.) Garay \& H.R.Sweet & HLO & $\mathrm{X}$ & $X$ & $\mathrm{X}$ & - & 09-080 \\
\hline Prescottia epiphyta Barb.Rodr. & HLF & $\mathrm{X}$ & $\mathrm{X}$ & $X$ & - & $08-063$ \\
\hline Promenaea paranaensis Schltr. & HLO & - & - & $\mathrm{X}$ & $\mathrm{X}$ & 08-092 \\
\hline Promenaea stapelioides (Link \& Otto) Lindl. & HLO & $\mathrm{X}$ & $\mathrm{X}$ & - & - & $08-156$ \\
\hline Prosthechea bulbosa (Vell.) W.E.Higgins & HLO & $\mathrm{X}$ & $\mathrm{X}$ & $\mathrm{X}$ & $\mathrm{X}$ & 08-078 \\
\hline Scaphyglottis modesta (Rchb.f.) Schltr. & HLO & $\mathrm{X}$ & $\mathrm{X}$ & - & - & 08-209 \\
\hline Sophronitis coccinea (Lindl.) Rchb.f. & HLO & - & - & $\mathrm{X}$ & $\mathrm{X}$ & 08-014 \\
\hline Specklinia grobyi (Bateman ex Lindl.) F.Barros & HLO & $\mathrm{X}$ & - & - & - & 08-197 \\
\hline Specklinia trifida (Lindl.) F.Barros & HLO & $\mathrm{X}$ & $\mathrm{X}$ & $\mathrm{X}$ & $\mathrm{X}$ & $08-218$ \\
\hline Specklinia sp.1 & HLO & $\mathrm{X}$ & - & $X$ & - & D10CM33 \\
\hline Stelis aprica Lindl. & HLO & $X$ & - & $\mathrm{X}$ & $\mathrm{X}$ & $08-212$ \\
\hline Stelis deregularis Barb.Rodr. & HLO & $\mathrm{X}$ & - & - & $\mathrm{X}$ & B26CI13 \\
\hline Stelis megantha Barb.Rodr. & HLO & $X$ & $X$ & $\mathrm{X}$ & $X$ & 08-004 \\
\hline Stelis papaquerensis Rchb.f. & HLO & - & - & $\mathrm{X}$ & - & $09-051$ \\
\hline Stelis sp.1 & HLO & $X$ & $\mathrm{X}$ & $\mathrm{X}$ & $\mathrm{X}$ & B16CM24 \\
\hline Stelis sp. 2 & HLO & - & $\mathrm{X}$ & $\mathrm{X}$ & - & D10CM07 \\
\hline Stelis sp.3 & HLO & - & - & $\mathrm{X}$ & - & 08-013 \\
\hline Stigmatosema polyaden (Vell.) Garay & HLF & $X$ & $\mathrm{X}$ & - & - & $09-145$ \\
\hline Vanilla parvifolia Barb.Rodr. & HMS & $\mathrm{X}$ & - & - & - & 191 \\
\hline Xylobium variegatum (Ruiz \& Pav.) Garay \& Dunst. & HLO & $\mathrm{X}$ & $\mathrm{X}$ & - & - & F06CI24 \\
\hline Zygopetalum crinitum Lodd. & HLP & - & - & - & $X$ & es \\
\hline Zygostates pellucida Rchb.f. & HLO & - & $\mathrm{X}$ & - & - & F08FM33 \\
\hline Zygostates pustulata (Kraenzl.) Schltr. & HLO & - & - & - & $\mathrm{X}$ & $09-187$ \\
\hline \multicolumn{7}{|l|}{ PIPERACEAE $(14-5,1 \%)$} \\
\hline Peperomia alata Ruiz \& Pav. & HLF & $\mathrm{X}$ & - & - & - & $08-200$ \\
\hline
\end{tabular}

Categorias ecológicas (Categ.: HLO-holoepífito obrigatório, HLP-holoepífito preferencial, HLF-holoepífito facultativo, HLA-holoepífito acidental, HMP-hemiepífito primário, HMS-hemiepífito secundário). Números de coleta do primeiro autor, exceto aqueles com iniciais de outros coletores

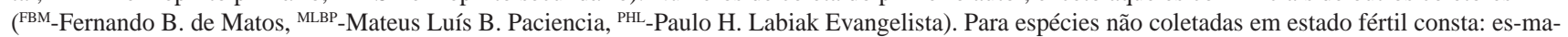
terial vegetativo, im-imagem digital, vi-material vivo em cultivo. De acordo com SEMA (Paraná 1995), constam categorias de espécies ameaçadas: *rara; **vulnerável; ***em perigo.

Ecological categories (Categ.: HLO-obligatory holoepiphyte, HLP-preferential holoepiphyte, HLF-facultative holoepiphyte, HLA-accidental holoepiphyte, HMP-primary hemiepiphyte, HMS-secondary holoepiphyte). Collect numbers of the first author, except those with abreviations of other collectors (FBM-Fernando B. de Matos, MLBP-Mateus Luís B. Paciencia, PHL-Paulo H. Labiak Evangelista). For species not collected in fertile state: es-vegetative material, im-digital image, vi-live material in cultive. According SEMA (Paraná 1995), are indicated the status of threatened species: *rare; **vulnerable; ***endangered. 
Tabela 1. Continuação...

\begin{tabular}{|c|c|c|c|c|c|c|}
\hline \multirow{3}{*}{$\begin{array}{c}\text { Família (no.-\% de espécies) } \\
\text { Espécie }\end{array}$} & \multirow[t]{3}{*}{ Categ. } & \multicolumn{4}{|c|}{ Faixa altitudinal (m) } & \multirow[t]{3}{*}{ Registro } \\
\hline & & 400 & 600 & 800 & 1000 & \\
\hline & & 500 & 700 & 900 & 1100 & \\
\hline Peperomia catharinae Miq. & HLP & - & $\mathrm{X}$ & $\mathrm{X}$ & $\mathrm{X}$ & 08-062 \\
\hline Peperomia corcovadensis Gardner & HLF & - & $\mathrm{X}$ & $\mathrm{X}$ & - & 09-082 \\
\hline Peperomia emarginella (Sw. ex Wikstr.) C. DC. & HLP & $\mathrm{X}$ & $\mathrm{X}$ & - & - & F19CI24 \\
\hline Peperomia glabella (Sw.) A. Dietr. & HLF & $\mathrm{X}$ & $\mathrm{X}$ & - & - & 08-036 \\
\hline Peperomia glazioui C. DC. & HLP & $\mathrm{X}$ & $\mathrm{X}$ & $\mathrm{X}$ & $\mathrm{X}$ & $08-137$ \\
\hline Peperomia cf. martiana Miq. & HLP & - & $\mathrm{X}$ & - & $\mathrm{X}$ & 08-017 \\
\hline Peperomia cf. nitida Dahlst. & HLP & - & $\mathrm{X}$ & - & - & F23FM04 \\
\hline Peperomia obtusifolia (L.) A. Dietr. & HLP & $\mathrm{X}$ & - & - & - & H21FA08 \\
\hline Peperomia pereskiifolia (Jacq.) Kunth & HLP & $\mathrm{X}$ & $\mathrm{X}$ & - & - & 194 \\
\hline Peperomia quadrifolia (L.) Kunth & HLP & $\mathrm{X}$ & $\mathrm{X}$ & $\mathrm{X}$ & - & 08-011 \\
\hline Peperomia tetraphylla (G. Forst.) Hook. \& Arn. & HLP & - & - & $\mathrm{X}$ & $\mathrm{X}$ & $09-239$ \\
\hline Peperomia trineuroides Dahlst. & HLP & - & $\mathrm{X}$ & - & $\mathrm{X}$ & 08-190 \\
\hline Peperomia sp.1 & HLP & - & $X$ & - & - & 08-006 \\
\hline \multicolumn{7}{|l|}{ RUBIACEAE $(1-0,4 \%)$} \\
\hline Hillia parasitica Jacq. & HMP & $\mathrm{X}$ & $\mathrm{X}$ & $\mathrm{X}$ & $\mathrm{X}$ & D21CM14 \\
\hline \multicolumn{7}{|l|}{ SOLANACEAE $(1-0,4 \%)$} \\
\hline Dyssochroma longipes Miers & HMP & - & $\mathrm{X}$ & $\mathrm{X}$ & - & es,im \\
\hline \multicolumn{7}{|l|}{ URTICACEAE $(2-0,7 \%)$} \\
\hline Coussapoa microcarpa (Schott) Rizzini & HMP & $\mathrm{X}$ & $\mathrm{X}$ & $\mathrm{X}$ & - & ES \\
\hline Pilea astrogramma Miq. & HLA & - & $\mathrm{X}$ & - & - & 08-046 \\
\hline
\end{tabular}

Pteridófitas

ASPLENIACEAE $(6-2,2 \%)$

Asplenium incurvatum Fée

Asplenium kunzeanum Klotzsch ex Rosenst.

Asplenium mucronatum C. Presl

Asplenium oligophyllum Kaulf.

Asplenium pteropus Kaulf.

Asplenium scandicinum Kaulf.

BLECHNACEAE (1-0,4\%)

Blechnum binervatum ssp. acutum (Desv.) R.M. Tryon \& Stolze

DRYOPTERIDACEAE (10-3,6\%)

Elaphoglossum brevipes (Kunze) T. Moore

Elaphoglossum glabellum J. Sm.

Elaphoglossum lingua (C. Presl) Brack.

Elaphoglossum nigrescens (Hook.) T. Moore ex Diels

Elaphoglossum ornatum (Mett. ex Kuhn) H. Christ

Elaphoglossum sp.1

Lomagramma guianensis (Aubl.) Ching

Polybotrya cylindrica Kaulf.

Rumohra adiantiformis (G. Forst.) Ching

Stigmatopteris heterocarpa (Fée) Rosenst.

\begin{tabular}{lccccl} 
HLP & $\mathrm{X}$ & $\mathrm{X}$ & $\mathrm{X}$ & $\mathrm{X}$ & B16FM02 \\
HLP & - & $\mathrm{X}$ & - & - & $08-048$ \\
HLP & $\mathrm{X}$ & - & - & - & $09-012$ \\
HLP & - & $\mathrm{X}$ & - & - & $08-053$ \\
HLP & $\mathrm{X}$ & - & - & - & $08-002$ \\
HLP & $\mathrm{X}$ & $\mathrm{X}$ & $\mathrm{X}$ & $\mathrm{X}$ & $08-028$ \\
& & & & & \\
HMS & $\mathrm{X}$ & - & - & $\mathrm{X}$ & $09-127$ \\
& & & & & \\
HLP & - & - & $\mathrm{X}$ & $\mathrm{X}$ & $08-237$ \\
HLP & $\mathrm{X}$ & - & $\mathrm{X}$ & - & $08-193$ \\
HLP & $\mathrm{X}$ & $\mathrm{X}$ & $\mathrm{X}$ & - & $08-167$ \\
HLP & $\mathrm{X}$ & - & - & - & 3172 PHL \\
HLP & $\mathrm{X}$ & $\mathrm{X}$ & $\mathrm{X}$ & $\mathrm{X}$ & $09-043$ \\
HLP & - & - & $\mathrm{X}$ & - & es \\
HMS & $\mathrm{X}$ & $\mathrm{X}$ & - & - & $08-208$ \\
HMS & $\mathrm{X}$ & - & - & - & $09-207$ \\
HLP & $\mathrm{X}$ & $\mathrm{X}$ & $\mathrm{X}$ & $\mathrm{X}$ & $08-077$ \\
HLA & $\mathrm{X}$ & - & - & - & H01FB04 \\
\hline
\end{tabular}

Categorias ecológicas (Categ.: HLO-holoepífito obrigatório, HLP-holoepífito preferencial, HLF-holoepífito facultativo, HLA-holoepífito acidental, HMP-hemiepífito primário, HMS-hemiepífito secundário). Números de coleta do primeiro autor, exceto aqueles com iniciais de outros coletores

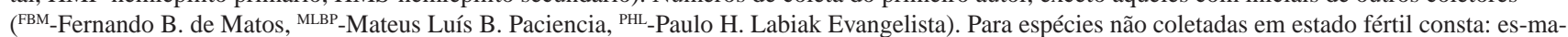
terial vegetativo, im-imagem digital, vi-material vivo em cultivo. De acordo com SEMA (Paraná 1995), constam categorias de espécies ameaçadas: *rara; **vulnerável; ***em perigo.

Ecological categories (Categ.: HLO-obligatory holoepiphyte, HLP-preferential holoepiphyte, HLF-facultative holoepiphyte, HLA-accidental holoepiphyte, HMP-primary hemiepiphyte, HMS-secondary holoepiphyte). Collect numbers of the first author, except those with abreviations of other collectors (FBM-Fernando B. de Matos, MLBP-Mateus Luís B. Paciencia, PHL-Paulo H. Labiak Evangelista). For species not collected in fertile state: es-vegetative material, im-digital image, vi-live material in cultive. According SEMA (Paraná 1995), are indicated the status of threatened species: *rare; **vulnerable; ***endangered. 
Tabela 1. Continuação...

\begin{tabular}{|c|c|c|c|c|c|c|}
\hline \multirow{3}{*}{$\begin{array}{c}\text { Família (no.-\% de espécies) } \\
\text { Espécie }\end{array}$} & \multirow[t]{3}{*}{ Categ. } & \multicolumn{4}{|c|}{ Faixa altitudinal (m) } & \multirow[t]{3}{*}{ Registro } \\
\hline & & 400 & 600 & 800 & 1000 & \\
\hline & & 500 & 700 & 900 & 1100 & \\
\hline \multicolumn{7}{|l|}{ HYMENOPHYLLACEAE $(15-5,4 \%)$} \\
\hline Abrodictyum rigidum (Sw.) Ebihara \& Dubuisson & HLF & - & $\mathrm{X}$ & - & - & $2171^{\mathrm{MLBP}}$ \\
\hline Didymoglossum cf. hymenoides (Hedw.) Copel. & HLP & $\mathrm{X}$ & - & - & - & H08FB06 \\
\hline Didymoglossum reptans (Sw.) C. Presl & HLP & - & - & - & $\mathrm{X}$ & $2187^{\mathrm{MLBP}}$ \\
\hline Hymenophyllum asplenioides (Sw.) Sw. & HLP & - & - & $\mathrm{X}$ & $\mathrm{X}$ & 09-109 \\
\hline Hymenophyllum caudiculatum Mart. & HLP & - & $\mathrm{X}$ & - & - & $2128^{\mathrm{MLBP}}$ \\
\hline Hymenophyllum fragile (Hedw.) C.V. Morton & HLP & - & - & - & $\mathrm{X}$ & $1163^{\mathrm{FBM}}$ \\
\hline Hymenophyllum polyanthos (Sw.) Sw. & HLP & $\mathrm{X}$ & $\mathrm{X}$ & $\mathrm{X}$ & $\mathrm{X}$ & $08-241$ \\
\hline Hymenophyllum pulchellum Schltdl. \& Cham. & HLP & - & - & $X$ & $X$ & B16CM25 \\
\hline Hymenophyllum vestitum (C. Presl) Bosch & HLP & - & - & $\mathrm{X}$ & $\mathrm{X}$ & $08-068$ \\
\hline Hymenophyllum sp.1 & HLP & - & - & $\mathrm{X}$ & - & 09-057 \\
\hline Polyphlebium angustatum (Carmich.) Ebihara \& Dubuisson & HLP & $\mathrm{X}$ & - & - & - & 57118 \\
\hline Polyphlebium diaphanum (Kunth) Ebihara \& Dubuisson & HLP & - & - & - & $\mathrm{X}$ & B08FB07 \\
\hline Polyphlebium pyxidiferum (L.) Ebihara \& Dubuisson & HLP & - & $\mathrm{X}$ & - & - & F04FB01 \\
\hline Trichomanes anadromum Rosenst. & HLP & - & - & $\mathrm{X}$ & - & 09-070 \\
\hline Vandenboschia radicans (Sw.) Copel. & HLP & $\mathrm{X}$ & $\mathrm{X}$ & - & $\mathrm{X}$ & $08-247$ \\
\hline \multicolumn{7}{|l|}{ LOMARIOPSIDACEAE $(1-0,4 \%)$} \\
\hline Lomariopsis marginata (Schrad.) Kuhn & HMS & $X$ & $\mathrm{X}$ & - & - & F07FB04 \\
\hline \multicolumn{7}{|l|}{ LYCOPODIACEAE $(7-2,5 \%)$} \\
\hline Huperzia acerosa (Sw.) Holub & HLO & $X$ & $\mathrm{X}$ & $X$ & $\mathrm{X}$ & $09-217$ \\
\hline Huperzia cf. biformis (Hook.) Holub & HLO & - & $\mathrm{X}$ & - & - & F08CI17 \\
\hline Huperzia flexibilis (Fée) B. Øllg. & HLO & $X$ & $X$ & - & - & $08-253$ \\
\hline Huperzia fontinaloides (Spring) Trevis. & HLO & - & - & $\mathrm{X}$ & - & D08CI07 \\
\hline Huperzia heterocarpon (Fée) Holub & HLO & $\mathrm{X}$ & - & $\mathrm{X}$ & $X$ & B10FA04 \\
\hline Huperzia hexasticha B. Øllg. \& P.G. Windisch & HLO & - & - & - & $\mathrm{X}$ & $2164^{\mathrm{MLBP}}$ \\
\hline Huperzia quadrifariata (Bory) Rothm. & HLO & - & $\mathrm{X}$ & $\mathrm{X}$ & $\mathrm{X}$ & $09-165$ \\
\hline \multicolumn{7}{|l|}{ OPHIOGLOSSACEAE $(1-0,4 \%)$} \\
\hline Ophioglossum palmatum L. & HLO & $X$ & - & $\mathrm{X}$ & $\mathrm{X}$ & 09-229 \\
\hline \multicolumn{7}{|l|}{ POLYPODIACEAE $(28-10,1 \%)$} \\
\hline Campyloneurum acrocarpon Fée & HLP & $\mathrm{X}$ & $\mathrm{X}$ & $\mathrm{X}$ & $\mathrm{X}$ & F17FA08 \\
\hline Campyloneurum minus Fée & HLP & - & $\mathrm{X}$ & - & - & $08-045$ \\
\hline Campyloneurum nitidum (Kaulf.) C. Presl & HLP & $\mathrm{X}$ & $\mathrm{X}$ & $\mathrm{X}$ & $\mathrm{X}$ & 08-081 \\
\hline Campyloneurum cf. repens (Aubl.) C. Presl & HLP & - & - & - & $\mathrm{X}$ & B22FM05 \\
\hline Campyloneurum rigidum $\mathrm{J} . \mathrm{Sm}$. & HLP & $\mathrm{X}$ & - & - & - & H05FM08 \\
\hline Cochlidium punctatum (Raddi) L.E. Bishop & HLO & - & $\mathrm{X}$ & $\mathrm{X}$ & $\mathrm{X}$ & В07CM07 \\
\hline Cochlidium serrulatum (Sw.) L.E. Bishop & HLO & - & $\mathrm{X}$ & $\mathrm{X}$ & $\mathrm{X}$ & В07CM02 \\
\hline Lellingeria apiculata (Kunze ex Klotzsch) A.R. Sm. \& R.C. Moran & HLP & - & - & $\mathrm{X}$ & $\mathrm{X}$ & $2124^{\mathrm{MLBP}}$ \\
\hline Lellingeria brevistipes (Mett. ex Kuhn) A.R. Sm. \& R.C. Moran & HLO & - & - & $\mathrm{X}$ & $\mathrm{X}$ & $08-067$ \\
\hline Melpomene pilosissima (M. Martens \& Galeotti) A.R. Sm. \& R.C. Moran & HLO & - & - & $\mathrm{X}$ & $\mathrm{X}$ & $08-233$ \\
\hline Microgramma percussa (Cav.) de la Sota & HLP & $\mathrm{X}$ & $\mathrm{X}$ & $\mathrm{X}$ & - & 08-116 \\
\hline Microgramma squamulosa (Kaulf.) de la Sota & HLP & $\mathrm{X}$ & $\mathrm{X}$ & $\mathrm{X}$ & $\mathrm{X}$ & $08-173$ \\
\hline Microgramma tecta (Kaulf.) Alston & HLP & $\mathrm{X}$ & $\mathrm{X}$ & - & - & $08-035$ \\
\hline
\end{tabular}

Categorias ecológicas (Categ.: HLO-holoepífito obrigatório, HLP-holoepífito preferencial, HLF-holoepífito facultativo, HLA-holoepífito acidental, HMP-hemiepífito primário, HMS-hemiepífito secundário). Números de coleta do primeiro autor, exceto aqueles com iniciais de outros coletores

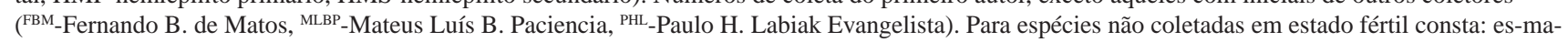
terial vegetativo, im-imagem digital, vi-material vivo em cultivo. De acordo com SEMA (Paraná 1995), constam categorias de espécies ameaçadas: *rara; **vulnerável; ***em perigo.

Ecological categories (Categ.: HLO-obligatory holoepiphyte, HLP-preferential holoepiphyte, HLF-facultative holoepiphyte, HLA-accidental holoepiphyte, HMP-primary hemiepiphyte, HMS-secondary holoepiphyte). Collect numbers of the first author, except those with abreviations of other collectors (FBM-Fernando B. de Matos, MLBP-Mateus Luís B. Paciencia, PHL-Paulo H. Labiak Evangelista). For species not collected in fertile state: es-vegetative material, im-digital image, vi-live material in cultive. According SEMA (Paraná 1995), are indicated the status of threatened species: *rare; **vulnerable; ***endangered. 
Tabela 1. Continuação...

\begin{tabular}{|c|c|c|c|c|c|c|}
\hline \multirow{3}{*}{$\begin{array}{c}\text { Família (nº.\% de espécies) } \\
\text { Espécie }\end{array}$} & \multirow[t]{3}{*}{ Categ. } & \multicolumn{4}{|c|}{ Faixa altitudinal (m) } & \multirow[t]{3}{*}{ Registro } \\
\hline & & 400 & $\begin{array}{l}600 \\
700\end{array}$ & 800 & 1000 & \\
\hline & & 500 & 700 & 900 & 1100 & \\
\hline Microgramma vacciniifolia (Langsd. \& Fisch.) Copel. & HLP & $\mathrm{X}$ & $\mathrm{X}$ & $\mathrm{X}$ & $\mathrm{X}$ & F11CE16 \\
\hline Micropolypodium achilleifolium (Kaulf.) Labiak \& F.B.Matos & HLO & - & - & $\mathrm{X}$ & $\mathrm{X}$ & $08-246$ \\
\hline Micropolypodium gradatum ( Baker ) Labiak \& F.B.Matos & HLO & - & - & $\mathrm{X}$ & $\mathrm{X}$ & 09-192 \\
\hline Niphidium crassifolium (L.) Lellinger & HLP & $\mathrm{X}$ & $\mathrm{X}$ & - & - & F18FM24 \\
\hline Pecluma recurvata (Kaulf.) M.G. Price & HLP & $\mathrm{X}$ & $\mathrm{X}$ & $\mathrm{X}$ & $\mathrm{X}$ & $08-057$ \\
\hline Pecluma sicca (Lindm.) M.G. Price & HLP & - & - & $\mathrm{X}$ & $\mathrm{X}$ & 08-064 \\
\hline Pecluma truncorum (Lindm.) M.G. Price & HLP & - & - & - & $\mathrm{X}$ & B09FB03 \\
\hline Pleopeltis astrolepis (Liebm.) E. Fourn. & HLP & $\mathrm{X}$ & $\mathrm{X}$ & $\mathrm{X}$ & $\mathrm{X}$ & D27CM08 \\
\hline Pleopeltis hirsutissima ( Raddi) de la Sota & HLP & $\mathrm{X}$ & $\mathrm{X}$ & $\mathrm{X}$ & $\mathrm{X}$ & 08-015 \\
\hline Pleopeltis macrocarpa (Bory ex Willd.) Kaulf. & HLP & $\mathrm{X}$ & $\mathrm{X}$ & $\mathrm{X}$ & $\mathrm{X}$ & B23FA02 \\
\hline Pleopeltis pleopeltidis ( Fée ) de la Sota & HLP & - & $\mathrm{X}$ & - & $\mathrm{X}$ & B04CE06 \\
\hline Pleopeltis pleopeltifolia (Raddi) Alston & HLP & $\mathrm{X}$ & $\mathrm{X}$ & $\mathrm{X}$ & $\mathrm{X}$ & $08-166$ \\
\hline Serpocaulon catharinae (Langsd. \& Fisch.) A.R. Sm. & HLP & $\mathrm{X}$ & $\mathrm{X}$ & $\mathrm{X}$ & $\mathrm{X}$ & 08-169 \\
\hline Serpocaulon triseriale (Sw.) A.R. Sm. & HLF & $\mathrm{X}$ & - & - & - & 09-119 \\
\hline Terpsichore reclinata (Brack.) Labiak & HLO & - & - & $\mathrm{X}$ & $\mathrm{X}$ & 08-065 \\
\hline \multicolumn{7}{|l|}{ PTERIDACEAE $(4-1,4 \%)$} \\
\hline Polytaenium cajenense (Desv.) Benedict & HLO & $\mathrm{X}$ & - & - & - & H08FM07 \\
\hline Polytaenium lineatum (Sw.) J. Sm. & HLO & $\mathrm{X}$ & $\mathrm{X}$ & $\mathrm{X}$ & $\mathrm{X}$ & B09FB04 \\
\hline Vittaria lineata (L.) Sm. & HLO & $\mathrm{X}$ & $\mathrm{X}$ & $\mathrm{X}$ & $\mathrm{X}$ & D09CI07 \\
\hline Vittaria cf. scabrida Klotzsch ex Fée & HLO & $\mathrm{X}$ & - & - & - & ES \\
\hline \multicolumn{7}{|l|}{ SELAGINELLACEAE $(1-0,4 \%)$} \\
\hline Selaginella macrostachya (Spring) Spring & HLA & - & - & $\mathrm{X}$ & - & $09-179$ \\
\hline
\end{tabular}

Categorias ecológicas (Categ.: HLO-holoepífito obrigatório, HLP-holoepífito preferencial, HLF-holoepífito facultativo, HLA-holoepífito acidental, HMP-hemiepífito primário, HMS-hemiepífito secundário). Números de coleta do primeiro autor, exceto aqueles com iniciais de outros coletores ( ${ }^{\mathrm{FBM}}$-Fernando B. de Matos, ${ }^{\mathrm{MLBP}}$-Mateus Luís B. Paciencia, ${ }^{\mathrm{PHL}}$-Paulo H. Labiak Evangelista). Para espécies não coletadas em estado fértil consta: es-material vegetativo, im-imagem digital, vi-material vivo em cultivo. De acordo com SEMA (Paraná 1995), constam categorias de espécies ameaçadas: *rara; **vulnerável; ***em perigo.

Ecological categories (Categ.: HLO-obligatory holoepiphyte, HLP-preferential holoepiphyte, HLF-facultative holoepiphyte, HLA-accidental holoepiphyte, HMP-primary hemiepiphyte, HMS-secondary holoepiphyte). Collect numbers of the first author, except those with abreviations of other collectors (FBM-Fernando B. de Matos, MLBP-Mateus Luís B. Paciencia, PHL-Paulo H. Labiak Evangelista). For species not collected in fertile state: es-vegetative material, im-digital image, vi-live material in cultive. According SEMA (Paraná 1995), are indicated the status of threatened species: *rare; **vulnerable; ***endangered.

Outras nove espécies, também encontradas em estado epifítico, não foram incluídas na listagem florística por se enquadrarem como epífitos efêmeros (Waechter 1992), ou seja, espécies terrícolas incapazes de completar seu ciclo biológico em estado epifítico. Foram três espécies arbóreas: Cabralea canjerana (Vell.) Mart., Prunus brasiliensis Dietrich e Myrsine umbellata Mart.; três espécies de bambus: Chusquea anelythroides Rupr. ex Döll, Chusquea cf. urelytra Hack. e Merostachys multiramea Hack.; e três espécies de lianas: Schlegelia parviflora (Oerst.) Monach., Marcgravia polyantha Delpino e Schwartzia brasiliensis (Choisy) Bedell ex Giraldo-Cañas. Todas representadas no ambiente epifítico por indivíduos jovens, cujo desenvolvimento tende à estagnação e à morte antes de completar o ciclo reprodutivo.

A elevada riqueza de espécies epífitas encontrada na encosta norte da Torre da Prata se destacou entre os estudos que abrangeram epífitas vasculares de Floresta Ombrófila Densa em todo o sul do Brasil, equiparando-se a valores encontrados para florestas equatoriais (Tabela 2).

Orchidaceae foi a família de maior riqueza na área estudada, com 103 espécies $(37,2 \%)$ e 43 gêneros $(39,1 \%)$. Também foram relevantes Bromeliaceae e Polypodiaceae, a primeira com 38 espécies $(13,4 \%)$ e nove gêneros $(8,2 \%)$, a segunda com 28 espécies $(10,1 \%)$ e 11 gêneros $(10,0 \%)$. Hymenophyllaceae apresentou 15 espécies $(5,4 \%)$, enquanto Araceae e Piperaceae apresentaram 14 espécies cada (5,1\% cada). Estas seis famílias foram responsáveis por $76,2 \%$ de toda a riqueza de epífitas registradas.

O gênero mais rico foi Vriesea, totalizando 18 espécies $(6,1 \%)$. Em seguida destacaram-se Peperomia com 14 espécies $(5,1 \%)$, Epidendrum com 12 espécies (4,3\%) e Maxillaria com 11 espécies (4,0\%). Huperzia, Hymenophyllum, Oncidium, Rhipsalis, Stelis e Pleurothallis foram representados por sete espécies $(2,5 \%)$ cada.

Em consulta ao Specieslink (2010), que reúne registros de coletas de 44 herbários do Brasil e do exterior, assim como através de uma revisão dos principais levantamentos florísticos de epífitas vasculares realizados em distintos tipos de vegetação do Paraná (Schütz-Gatti 2000, Petean 2002, 2009, Borgo \& Silva 2003, Kersten \& Kuniyoshi 2006, Kersten \& Silva 2002, 2006, Kersten et al. 2009, Cervi \& Borgo 2007, Dettke et al. 2008,), verificou-se que 10 das espécies registradas na Serra da Prata possuem apenas um ou dois registros para o Paraná. É o caso de Rhipsalis trigona, Rhipsalis burchellii, Elaphoglossum glabellum, Cirrhaea dependens, 
Tabela 2. Estudos sobre epífitas vasculares realizados no Brasil e em outros países americanos, organizados de forma decrescente pela riqueza florística em espécies (spp.), além dos gêneros (gen) e famílias (fam); fitofisionomia (Fitofis.) de ocorrência: floresta tropical de forma genérica (Fl.Trop), Floresta Ombrófila Densa (Fod, podendo ser S-submontana, M-montana ou A-altomontana), Floresta Ombrófila Mista (Fom) e Formação Pioneira de Influência Marinha (Fpim); precipitação média anual (Precip.).

Table 2. Studies on vascular epiphitic flora in Brazil and others Central and South American countries, organized in descending order of species richness (spp.), genera (gen) and families (fam); Occurrence formation (Fitofis.): Tropical Rainforest in a generic form (Fl.Trop), Atlantic Rainforest (Fod, S-submontane, M-montane or A-altomontane), Araucaria Forest (Fom) and Restinga Forest (Early Formation with Marine Influence) (Fpim); average annual precipitation (Precip.); and sampled area.

\begin{tabular}{lccclccl}
\hline \multicolumn{1}{c}{ Local } & Spp. & Gen & Fam & Fitofis. & $\begin{array}{c}\text { Precip. } \\
(\mathbf{m m})\end{array}$ & $\begin{array}{c}\text { Área } \\
\text { (ha) }\end{array}$ & Referência \\
\hline Centinela, Equador & 337 & - & 19 & Fl.Trop & 3000 & - & Gentry \& Dodson (1987a) \\
Serra da Prata, PR & $\mathbf{2 7 7}$ & $\mathbf{1 0 9}$ & $\mathbf{3 0}$ & Fod.S/M & $\mathbf{2 2 9 0}$ & $\mathbf{6 , 3}$ & Este estudo \\
Monteverde, Costa Rica & 256 & 105 & 36 & Fl.Trop & 2500 & 4,0 & Ingram et al. (1996) \\
Planície Costeira, RS & 250 & 106 & 27 & Fpim & 1300 & - & Waechter (1992) \\
Rio Palenque, Equador & 238 & - & 18 & Fl.Trop & 2980 & - & Gentry \& Dodson (1987a) \\
Rio Caquetá, Colômbia & 206 & 73 & 22 & Fl.Trop & 3060 & 0,75 & Benavides et al. (2005) \\
Sehuencas, Bolívia & 204 & - & 17 & Fl.Trop & 5000 & 0,4 & Ibisch (1996) \\
Carbonera, Venezuela & 191 & - & 20 & Fl.Trop & 1500 & 0,08 & Engwald (1999) \\
Salto Morato, PR & 176 & 78 & 26 & Fod.S & 2000 & 3,2 & Schütz-Gatti (2000) \\
Ilha do Cardoso, SP & 166 & 78 & 22 & Fpim & 2027 & 10,2 & Breier (2005) \\
Morro da Mina, PR & 159 & 80 & 22 & Fod.S & 2000 & - & Petean (2009) \\
Parque Carlos Botelho, SP & 158 & 77 & 24 & Fod.S & 1591 & 10,2 & Breier (2005) \\
Morro da Tromba, SC & 145 & 69 & 22 & Fod.S/M & 2205 & - & Mancinelli \& Esemann-Quadros (2007) \\
Piraquara, PR & 140 & 68 & 23 & Fod/Fom & 1500 & - & Kersten (2006) \\
Torres, RS & 115 & 56 & 15 & Fpim & 1452 & - & Waechter (1986) \\
Ilha do Mel, PR & 103 & 53 & 19 & Fpim & 1960 & 0,3 & Kersten \& Silva (2006) \\
Piraquara, PR & 99 & 56 & 17 & Fod/Fom & 1500 & - & Hertel (1949) \\
Pico do Marumbi, PR & 97 & 53 & 14 & Fod.A & 3000 & 0,07 & Petean (2002) \\
\hline
\end{tabular}

Dados de riqueza florística foram ajustados considerando novos enquadramentos taxonômicos, além de serem excluídos táxons hemiparasitas e epífitos efêmeros. The floristic richness data were adjusted considering new taxonomic classifications. Hemiparasites and ephemeral epiphytes were excluded.

Epidendrum proligerum, Gomesa glaziovii, Epidendrum tridactylum, Eurystyles lorenzii, Stelis aprica e Vanilla parvifolia. De outras sete espécies não foi encontrado nenhum registro para o Paraná, nas fontes consultadas: Acianthera glanduligera, Campylocentrum sellowii, Epidendrum addae, Maxillaria cleistogama, Pleurothallis parviflora, Prescottia epiphyta e Zygostates pellucida.

Do total de espécies abrangidas, seis se destacaram por fazerem parte da "Lista Vermelha de Plantas Ameaçadas de Extinção no Estado do Paraná" (Paraná 1995), são elas: Voyria aphylla, Anathallis obovata, Eurystyles lorenzii, Lepanthopsis floripecten (Figura 2e), Racinaea spiculosa e Leptotes bicolor (Figura 2f). Nenhuma das espécies registradas é citada em listas de espécies ameaçadas com abrangência nacional (Fundação... 2005, Giulietti et al. 2008) ou internacional (International... 2011).

A maioria das espécies se enquadra como holoepífito obrigatório ou preferencial (Tabela 3), que juntos constituem o grupo de holoepífitos característicos (ou verdadeiros), perfazendo 83,0\%. As pteridófitas e monocotiledôneas se destacam entre os holoepífitos característicos representando $88,3 \%$ desta categoria. Na categoria dos holoepífitos acidentais se destacam as eudicotiledôneas, com 57\% das espécies deste grupo. A categoria dos hemiepífitos foi constituída predominantemente por monocotiledôneas e eudicotiledôneas.

Dentre as famílias representadas por mais de uma espécie, Araceae e Dryopteridaceae foram as que apresentaram maior heterogeneidade nas categorias ecológicas, com espécies em quase todas elas (Tabela 4). Cactaceae, Lycopodiaceae e Pteridaceae se caracterizaram por ocorrer apenas como holoepífitos obrigatórios. A família Orchidaceae, apesar de possuir espécies de holoepífitos preferenciais ou facultativos, e até mesmo um hemiepífito secundário, concentrou a maior parte de sua riqueza $(95,1 \%)$ na categoria dos holoepífitos obrigatórios. Apocynaceae (Figura 2d) foi representada apenas por hemiepífitos, sendo que Begoniaceae e Urticaceae ocorreram com hemiepífitos e holoepífitos acidentais.

A faixa altitudinal que apresentou maior riqueza foi a dos 400 500 m, com 188 espécies $(67,9 \%)$. Nas faixas dos 600-700 m e 800$900 \mathrm{~m}$ os valores de riqueza foram intermediários, respectivamente $163(58,8 \%)$ e $162(58,5 \%)$ espécies. A faixa dos 1.000-1.100 m foi a que apresentou a menor riqueza, 121 espécies (43,7\%).

No que se refere à distribuição por altitude, apenas 54 espécies $(19,5 \%)$ apresentaram distribuição ampla, sendo registradas em todas as quatro faixas altitudinais preestabelecidas. Restritas às baixas altitudes, 131 espécies $(47,3 \%)$ foram registradas somente abaixo dos 700 m s.n.m. (inclusive), sendo $40(14,4 \%)$ exclusivas da faixa 400-500 m. Por outro lado, 54 espécies (19,5\%) foram encontradas somente acima dos $800 \mathrm{~m}$ s.n.m. (inclusive), das quais $12(4,3 \%)$ apenas na faixa 1.000-1.100 m.

Na Tabela 5 é apresentada a matriz de similaridade florística entre quatro patamares altitudinais da área de estudo e outras estações de Floresta Ombrófila Densa pesquisadas no Paraná e em São Paulo.

\section{Discussão}

A riqueza florística encontrada na encosta norte da Torre da Prata foi, até o momento, a maior já registrada em estudos sobre epífitas vasculares de Floresta Ombrófila Densa em todo o sul do Brasil. Nos estados sulinos, além dos limites da Floresta Ombrófila Densa, 
Tabela 3. Classificação das epífitas vasculares, registradas em Floresta Ombrófila Densa na Serra da Prata, Morretes, PR, segundo categorias ecológicas (HLOholoepífito obrigatório, HLP-holoepífito preferencial, HLF-holoepífito facultativo, HLA-holoepífito acidental, HMP-hemiepífito primário, HMS-hemiepífito secundário) dentro dos seus respectivos táxons.

Table 3. Vascular epiphytes of a Atlantic Rainforest in the Prata Mountain Range, Morretes, Paraná State, classified according to their ecological categories (HLO-obligatory holoepiphyte, HLP-preferential holoepiphyte, HLF-facultative holoepiphyte, HLA-accidental holoepiphyte, HMP-primary hemiepiphyte, HMS-secondary holoepiphyte).

\begin{tabular}{|c|c|c|c|c|c|c|c|c|c|c|c|c|}
\hline \multirow{2}{*}{$\begin{array}{c}\text { Grupo } \\
\text { taxonômico }\end{array}$} & \multicolumn{2}{|c|}{ HLO } & \multicolumn{2}{|c|}{ HLP } & \multicolumn{2}{|c|}{ HLF } & \multicolumn{2}{|c|}{ HLA } & \multicolumn{2}{|c|}{ HMP } & \multicolumn{2}{|c|}{ HMS } \\
\hline & $\mathbf{N}$ & $\%$ & $\mathbf{N}$ & $\%$ & $\mathbf{N}$ & $\%$ & $\mathbf{n}$ & $\%$ & $\mathbf{n}$ & $\%$ & $\mathbf{N}$ & $\%$ \\
\hline Monilophyta & 12 & 4,3 & 47 & 17,0 & 2 & 0,7 & 1 & 0,4 & - & - & 4 & 1,4 \\
\hline Lycophyta & 7 & 2,5 & - & - & - & - & 1 & 0,4 & - & - & - & - \\
\hline Magnollídea & - & - & 11 & 4,0 & 3 & 1,1 & - & - & - & - & - & - \\
\hline Monocotiledônea & 109 & 39,4 & 28 & 10,1 & 7 & 2,5 & 1 & 0,4 & 3 & 1,1 & 7 & 2,5 \\
\hline Eudicotiledônea & 11 & 4,0 & 5 & 1,8 & - & - & 4 & 1,4 & 12 & 4,3 & 2 & 0,7 \\
\hline Total & 139 & 50,2 & 91 & 32,9 & 12 & 4,3 & 7 & 2,5 & 15 & 5,4 & 13 & 4,7 \\
\hline
\end{tabular}

Tabela 4. Distribuição percentual de epífitas vasculares, registradas em Floresta Ombrófila Densa na Serra da Prata, Morretes, PR, segundo as categorias ecológicas (HLO-holoepífito obrigatório, HLP-holoepífito preferencial, HLF-holoepífito facultativo, HLA-holoepífito acidental, HMP-hemiepífito primário, HMS-hemiepífito secundário), considerando apenas famílias com mais de uma espécie.

Table 4. Percentual distribution of vascular epiphytes of a Atlantic Rainforest in the Prata Mountain Range, Morretes, Paraná State, according to their ecological categories (HLO-obligatory holoepiphyte, HLP-preferential holoepiphyte, HLF-facultative holoepiphyte, HLA-accidental holoepiphyte, HMP-primary hemiepiphyte, HMS-secondary holoepiphyte), considering families with more than one species.

\begin{tabular}{cccccccccccccccccc}
\hline & Apo & Ara & Asp & Beg & Bro & Cac & Dry & Ges & Hym & Lyc & Mel & Orc & Pip & Pol & Pte & Urt \\
\hline HLO & - & 7,1 & - & - & 29,7 & 100 & 60,0 & - & - & 100 & 66,7 & 94,2 & - & 25,0 & 100 & - \\
HLP & - & 21,4 & 100 & - & 62,2 & - & 10,0 & 100 & 93,3 & - & - & 1,9 & 78,6 & 71,4 & - & - \\
HLF & - & - & - & - & 8,1 & - & - & - & 6,7 & - & - & 2,9 & 21,4 & 3,6 & - & - \\
HLA & - & 7,1 & - & 33,3 & - & - & 10,0 & - & - & - & 33,3 & - & - & - & - & 50,0 \\
HMP & 100 & 21,4 & - & - & - & - & - & - & - & - & - & - & - & - & - & 50,0 \\
HMS & - & 42,9 & - & 66,7 & - & - & 20,0 & - & - & - & - & 1,0 & - & - & - & - \\
\hline
\end{tabular}

Apo-Apocynaceae, Ara-Araceae, Asp-Aspleniaceae, Beg-Begoniaceae, Bro-Bromeliaceae, Cac-Cactaceae, Dry-Dryopteridaceae, Ges-Gesneriaceae,

Hym-Hymenophyllaceae, Lyc-Lycopodiaceae, Mel-Melastomataceae, Orc-Orchidaceae, Pip-Piperaceae, Pol-Polypodiaceae, Pte-Pteridaceae, Urt-Urticaceae.

Tabela 5. Similaridade florística (índice de Jaccard) entre quatro patamares altitudinais da área de estudo (Serra da Prata) e outras seis áreas de Floresta Ombrófila Densa: Morro da Mina-PR (Petean 2009), Salto Morato-PR (Schütz-Gatti 2000), Parque Carlos Botelho-SP (Breier 2005), Ilha do Mel-PR (Kersten \& Silva 2005), Serra do Marumbi-PR (Petean 2002) e Piraquara-PR (Kersten 2006), considerando somente epífitas determinadas em nível de espécie.

Table 5. Floristic similarity (Jaccard index) for four altitudinal levels of the study area (Prata Mountain Range) and others seis Atlantic Rainforest sites: Morro da Mina-PR (Petean 2009), Salto Morato-PR (Schütz-Gatti 2000), Carlos Botelho Park-SP (Breier 2005), Ilha do Mel-PR (Kersten \& Silva 2005), Serra do Marumbi-PR (Petean 2002) and Piraquara-PR (Kersten 2006), considering epiphytes identified at species level.

\begin{tabular}{|c|c|c|c|c|c|c|c|c|c|}
\hline & $\begin{array}{c}\text { S. Prata } \\
400 / 500 \mathrm{~m}\end{array}$ & $\begin{array}{c}\text { S. Prata } \\
600 / 700 \mathrm{~m}\end{array}$ & $\begin{array}{c}\text { S. Prata } \\
800 / 900 \mathrm{~m}\end{array}$ & $\begin{array}{c}\text { S.Prata } \\
1000 / 1100 \mathrm{~m}\end{array}$ & $\begin{array}{c}\text { Morro } \\
\text { da Mina }\end{array}$ & $\begin{array}{c}\text { Salto } \\
\text { Morato }\end{array}$ & $\begin{array}{c}\text { Carlos } \\
\text { Botelho }\end{array}$ & $\begin{array}{c}\text { Ilha } \\
\text { do Mel }\end{array}$ & Piraquara \\
\hline S. Prata $600 / 700 \mathrm{~m}$ & 0,59 & - & - & - & - & - & - & - & - \\
\hline S. Prata $800 / 900 \mathrm{~m}$ & 0,42 & 0,47 & - & - & - & - & - & - & - \\
\hline S. Prata $1000 / 1100 \mathrm{~m}$ & 0,30 & 0,35 & 0,53 & - & - & - & - & - & - \\
\hline Morro da Mina & 0,40 & 0,32 & 0,29 & 0,20 & - & - & - & - & - \\
\hline Salto Morato & 0,37 & 0,32 & 0,29 & 0,18 & 0,44 & - & - & - & - \\
\hline Carlos Botelho & 0,33 & 0,25 & 0,22 & 0,15 & 0,33 & 0,34 & - & - & - \\
\hline Ilha do Mel & 0,28 & 0,23 & 0,21 & 0,16 & 0,38 & 0,38 & 0,28 & - & - \\
\hline Piraquara & 0,19 & 0,20 & 0,23 & 0,25 & 0,15 & 0,16 & 0,14 & 0,14 & - \\
\hline Serra do Marumbi & 0,14 & 0,17 & 0,29 & 0,34 & 0,11 & 0,10 & 0,07 & 0,09 & 0,20 \\
\hline
\end{tabular}

apenas um amplo levantamento realizado por Kersten \& Kuniyoshi (2006) suplantou o presente estudo em termos de riqueza, alcançando 349 espécies. No entanto, abrangeu área 18 vezes maior (113 ha) e de grande extensão geográfica, com uma distância de mais de $90 \mathrm{~km}$ entre os extremos, englobando espécies de três fitofisionomias florestais distintas, e tendo 140 espécies contabilizadas através de registros obtidos em herbários ou em outros estudos. Também relevante foi a riqueza registrada por Waechter (1992) na planície costeira do Rio Grande do Sul, muito próxima dos valores encontrados na Serra da Prata, mas também referente a uma extensa área de amostragem, com mais de $200 \mathrm{~km}$ de distância entre seus extremos.

A riqueza de epífitas registrada na Serra da Prata se equipara com a de outros estudos realizados na América Central e no norte da América do Sul, sendo em geral mais elevada do que a maioria dos 
valores encontrados em outros levantamentos. Dentre os avaliados, apenas Gentry \& Dodson (1987a) e Ingram et al. (1996) registraram valores próximos aos da Serra da Prata, em florestas do Equador e da Costa Rica, sendo particularmente expressiva a riqueza encontrada em Centinela (Equador). No entanto, é importante ressaltar que no presente estudo abrangeu-se uma área relativamente maior e também duas fitofisionomias florestais distintas (Submontana e Montana), fatores que certamente favoreceram alcançar valor de riqueza equiparável aos encontrados em florestas equatoriais.

A condição climática de elevada umidade com precipitação bem distribuída ao longo do ano (Instituto... 1978, Instituto Paranaense... 1991) é uma das principais causas da elevada riqueza florística de epífitas na Torre da Prata. Gentry \& Dodson (1987b) destacam a umidade como um dos fatores determinantes para a grande riqueza de espécies epifíticas nos neotrópicos.

No entanto, o aspecto determinante para a elevada riqueza registrada foi a variação altitudinal da encosta estudada. Este gradiente possui $800 \mathrm{~m}$ de desnível ao longo de apenas cerca de $2.300 \mathrm{~m}$ de distância horizontal. Um relevo de tal forma abrupto proporciona situações ambientais diferenciadas, além de englobar dois tipos climáticos distintos, o Cfa e o Cfb, de acordo com a classificação de Koeppen, que determinam associações florísticas também distintas (Blum \& Roderjan 2007, Blum et al. 2011). Além da diversificação proporcionada pelo clima, Blum (2006) destaca que o relevo movimentado propicia diferenciações estruturais na floresta, como redução na altura do dossel e uma dinâmica mais intensa de formação de clareiras, ambos aspectos relacionados aos solos mais rasos, e que podem aumentar a incidência dos raios solares no interior da floresta, favorecendo a diversificação de ambientes para a comunidade epifítica nos estratos inferiores, fustes e copas dominadas. A forte declividade também favorece a insolação lateral das copas de árvores do dossel, aspecto relatado por Leme (1993), potencializando ainda mais o desenvolvimento da comunidade epifítica.

O componente epifítico vascular é responsável por considerável parcela da riqueza total de florestas tropicais em todo o mundo, sendo muitas vezes equivalente ou superior em espécies do que o componente arbóreo (Gentry \& Dodson 1987a, Hartshorn \& Hammel 1994, Kersten \& Silva 2006). Na Serra da Prata, esta tendência foi comprovada através da comparação com os dados coletados por Blum (2006), que registrou 273 espécies de árvores ou arbustos na mesma área de estudo. Kersten (2006), comparando estudos florísticos sobre epífitas e arbóreas no Paraná, relatou que o número de espécies epifíticas possivelmente exceda o de arbóreas.

Reafirmando uma tendência observada na grande maioria dos estudos sobre epífitas no Brasil (Waechter 1992, Dittrich et al. 1999, Schütz-Gatti 2000, Petean 2002, 2009, Borgo \& Silva 2003, Giongo \& Waechter 2004, Breier 2005, Kersten \& Silva 2002, Kersten et al. 2009, 2006, Mancinelli \& Esemann-Quadros 2007, Buzatto et al. 2008), as famílias mais ricas na Serra da Prata foram Orchidaceae, Bromeliaceae e Polypodiaceae. É preciso ressaltar que Orchidaceae foi sempre a principal família em todos os estudos citados, com alternância entre Bromeliaceae e Polypodiaceae na segunda e terceira colocações.

Orchidaceae é, realmente, a mais importante família dentre as epífitas vasculares de todo o mundo, representando mais da metade da flora epifítica (Madison 1977, Gentry \& Dodson 1987b, Benzing 1990). Na Serra da Prata, a riqueza de Orchidaceae (103) foi muito expressiva, sendo que poucos estudos no País obtiveram valor tão elevado para esta família. A maioria dos estudos sobre epífitas vasculares em Floresta Ombrófila Densa no Brasil abrangeu riqueza total de Orchidaceae entre 40 e 60 espécies (Schütz-Gatti 2000, Petean 2002, 2009, Breier 2005, Kersten \& Silva 2006, Mancinelli \& Esemann-Quadros 2007).
Grande parte da riqueza de Orchidaceae é devida à ocorrência de gêneros neotropicais que apresentam elevado número de espécies como Pleurothallis, Maxillaria, Epidendrum, Oncidium e Stelis (Benzing 1990). De fato, na Serra da Prata os gêneros Epidendrum, Maxillaria, Stelis, Oncidium e Pleurothallis, nesta ordem, foram os mais ricos em Orchidaceae, totalizando 44 espécies. Considerando ainda os gêneros desmembrados de Pleurothallis (Acianthera, Anathallis, Panmorphia e Specklinia) (Pridgeon \& Chase 2001, Pridgeon et al. 2001), mais 11 espécies poderiam ser somadas a este montante.

Analisando diversos estudos sobre epífitas vasculares no Brasil, Kersten (2010) descreve que a família Orchidaceae representa um percentual médio de $45,8 \%$ das espécies observadas nos levantamentos. Em mesmo procedimento, considerando cinco estudos realizados na América Tropical, Ingram et al. (1996) chegaram a uma porcentagem de 35,2\% para esta família, demonstrando que a proporção de orquídeas encontrada para a Serra da Prata está dentro do intervalo esperado.

A riqueza de Bromeliaceae na Serra da Prata também foi considerável, com destaque para o gênero Vriesea (Figura 2c) demonstrando, sobretudo, a grande influência exercida pela variação altitudinal na diversificação da florística. Kaehler (2008) encontrou 34 espécies de bromélias nas florestas da Serra do Marumbi, maciço próximo ao da Serra da Prata, enquanto Schütz-Gatti (2000) e Petean (2009) registraram, respectivamente, 31 e 24 espécies em Antonina e Guaraqueçaba, municípios vizinhos ao de Morretes. Na Ilha GrandeRJ, Nunes-Freitas (2004) encontrou 45 espécies de Bromeliaceae em levantamento sistemático quantitativo especificamente voltado para esta família, que abrangeu também espécies terrícolas.

Segundo Fontoura et al. (1991), Leme (1993) e Martinelli et al. (2008), a floresta da encosta atlântica é uma das mais ricas em bromélias, que vegetam praticamente em todos os estratos. A floresta atlântica é considerada um dos centros de especiação e dispersão de alguns gêneros de Bromeliaceae (Leme 1998, 2000, Benzing 2000), aspecto que vem resultando em um aumento no número de espécies recém descritas nos últimos anos, potencializado pela intensificação nas pesquisas em áreas ainda pouco conhecidas (Fontoura et al. 1991). Além da descoberta de novas espécies, muitas pesquisas estão sendo feitas no sentido de organizar a família no âmbito taxonômico (Martinelli et al. 2008), o que contribuiu para que quatro espécies registradas na Serra da Prata permanecessem temporariamente com identificação de morfoespécie (Vriesea aff. tijucana, Vriesea sp.1, Vriesea sp.2 e Vriesea sp.3), sendo que duas delas representam espécies ainda não descritas.

Dentre as angiospermas, destacaram-se ainda as famílias Araceae e Piperaceae, também relevantes em diversos estudos sobre epífitas vasculares (Waechter 1986, 1992, Steege \& Cornelissen 1989, SchützGatti 2000; Rogalski \& Zanin 2003, Benavides et al. 2005, Breier 2005, Kersten \& Silva 2006, Cervi \& Borgo 2007, Petean 2009). Araceae, apesar de ser considerada por Benzing (1990) a segunda maior família de epífitas vasculares do mundo, em geral tende a apresentar menor quantidade de espécies do que Bromeliaceae na região da floresta atlântica, fato constatado na maioria dos estudos desencadeados neste âmbito geográfico. Ainda assim, a riqueza de Araceae constatada na Serra da Prata foi relevante, tendo sido superior às encontradas em áreas com fitofisionomia semelhante, como Morro da Mina ( $\mathrm{n}=11)$, Salto Morato $(\mathrm{n}=9)$ e PE Carlos Botelho $(\mathrm{n}=13)$.

As pteridófitas representaram $26,7 \%$ de todas as espécies de epífitas vasculares registradas na Serra da Prata. Esta proporção corresponde às observadas em outros estudos com o mesmo enfoque: Ingram et al. (1996) registraram uma percentagem de 22,0\% de pteridófitas em Monteverde (Costa Rica); Schütz-Gatti (2000), Breier (2005), Kersten \& Silva (2006) e Petean (2009) encontraram 
valores entre 21,4 e 27,2\% de pteridófitas em áreas de Floresta Ombrófila Densa no Paraná e em São Paulo. No entanto, nenhum dos estudos citados registrou tamanha riqueza em espécies, sendo a área de Monteverde a que mais se aproximou $(n=56)$. Kersten (2006) amostrou 53 espécies em uma área de transição entre Florestas Ombrófilas Mista e Densa em Piraquara, PR. Considerando estudos que enfocaram exclusivamente pteridófitas, Dittrich et al. (2005) registraram 51 espécies de pteridófitas epífitas na Serra do Marumbi, enquanto Labiak \& Prado (1998) encontraram 59 espécies em Floresta Ombrófila Densa da planície litorânea em Santa Catarina.

Particularmente importantes foram Polypodiaceae e Hymenophyllaceae. Estas famílias, somadas a Dryopteridaceae, compõem $71,6 \%$ do total de pteridófitas e $19,1 \%$ de toda a flora epifítica registrada. Polypodiaceae figura como a mais expressiva em riqueza dentre as pteridófitas epífitas, fato constatado na grande maioria dos estudos com este enfoque no Brasil.

Por outro lado, a riqueza de Hymenophyllaceae nem sempre aparece de forma tão significativa em estudos sobre epífitas. $\mathrm{Na}$ maioria dos estudos esta família não ultrapassa a riqueza de 10 espécies (Waechter 1992, Schütz-Gatti 2000, Breier 2005, Kersten \& Silva 2006, Petean 2009). O principal aspecto que influenciou a elevada riqueza de Hymenophyllaceae da Serra da Prata foi que cinco espécies encontradas durante estudo realizado por Paciencia (2008) no mesmo local foram somadas às 10 registradas em campo no presente estudo. De qualquer modo, este fato demonstra o potencial de riqueza das Hymenophyllaceae, avaliada por Benzing (1990) em cerca de 400 espécies epifíticas no mundo, e também a tendência de esta família ser subestimada na maioria dos estudos, principalmente em função do pequeno porte de seus indivíduos, o que dificulta sua visualização.

A relevância de estudos que abordem principalmente sinúsias não arbóreas no Paraná, com enfoque na Floresta Ombrófila Densa, é salientada pela constatação de espécies epífitas com nenhum ou poucos registros para o Paraná, de acordo com as fontes consultadas. Além disso, a existência de espécies raras e ameaçadas de extinção no Paraná reforça a importância ecológica desta região, enfatizando a existência do Parque Nacional Saint-Hilaire/Lange para a conservação de sua biodiversidade. Não há dúvida que a continuidade dos levantamentos florísticos deva elevar o número de espécies raras e ameaçadas registradas.

A predominância de espécies na categoria ecológica dos holoepífitos característicos $(83,0 \%)$, que inclui holoepífitos obrigatórios e preferenciais, é um padrão confirmado por vários estudos que focaram a flora epifítica no Brasil, como Waechter (1992) $(86,8 \%)$, Kersten \& Silva (2002) $(84,0 \%)$, Borgo \& Silva (2003) $(83,3 \%)$, Gonçalves \& Waechter (2003) (89,6\%), Rogalski \& Zanin (2003) (77\%), Giongo \& Waechter (2004) (77,0\%), SchützGatti (2000) (76,0\%), Buzatto et al. (2008) $(84,1 \%)$ e Kersten et al. (2009) $(89,0 \%)$, entre outros.

Como holoepífitos facultativos destacaram-se três bromélias do gênero Nidularium, ( $N$. amazonicum, $N$. campo-alegrensis e $N$. innocentii), espécies umbrófilas comumente encontradas tanto como terrícolas quanto como rupícolas ou epífitas nas porções baixas dos fustes. Orquidáceas de raiz carnosa, como Malaxis excavata, Prescottia epiphyta e Stigmatosema polyaden também não apresentaram preferência entre o solo e as árvores, mesmo sendo morfologicamente mais semelhantes às orquídeas terrícolas. Por fim, algumas espécies de Peperomia (P. alata, $P$. corcovadensis e P. glabella) podem ocorrer tanto como epífitas quanto como rupícolas nos matacões rochosos da floresta.

Foram poucos os registros de holoepífitos acidentais, destacando-se principalmente espécies herbáceas tipicamente terrícolas, que acabam colonizando, em geral, as porções mais baixas dos fustes. Foi o caso de Anthurium acutum, Begonia paleata, Stigmatopteris heterocarpa,
Bertolonia mosenii, Selaginella macrostachya e Pilea astrogramma. Um registro inusitado foi o de Voyria aphylla, uma saprófita terrícola bastante rara, encontrada na copa externa de uma árvore com $20 \mathrm{~m}$ de altura.

Os hemiepífitos abrangem 10,1\% das espécies, com predomínio de Araceae, aspecto já exemplificado por Benzing (1989, 1995) e também constatado por Nieder et al. (2000), que registraram 12 espécies de aráceas hemiepífitas em uma floresta pluvial da Venezuela. Em áreas próximas à Serra da Prata, Schütz-Gatti (2000) e Petean (2009) encontraram hemiepífitas em proporções semelhantes, em torno de $9 \%$, sendo que em ambos os estudos a família Araceae também predominou nesta categoria ecológica.

Cinco espécies de hemiepífitos primários merecem destaque, por constituírem indivíduos lenhosos que desenvolvem porte arbóreo sobre seus forófitos. Foi o caso de Dendropanax cuneatus, Clusia criuva, Spirotheca passifloroides, Ficus enormis e Coussapoa microcarpa. Destas, apenas D. cuneatus não apresenta hábito constritor, sendo que as demais podem desenvolver raízes estrangulantes a ponto de proporcionar a morte do forófito, embora isto não ocorra em todos os casos.

Dentre os hemiepífitos secundários é relevante ressaltar a ocorrência de Vanilla parvifolia, uma Orchidaceae cujo hábito foge à regra do holoepifitismo seguida pela grande maioria dos representantes da família e, além disso, constitui o primeiro registro em estudos de epífitas vasculares de Floresta Ombrófila Densa de encosta no Paraná.

No que se refere à distribuição por faixa altitudinal, a concentração da riqueza de espécies na faixa dos 400-500 m já era esperada, já que nestas cotas ocorre a formação Submontana (Blum \& Roderjan, 2007), que apresenta maior diversidade florística dentro da região fitoecológica, devido à combinação de fatores ambientais favoráveis como solos profundos e desenvolvidos, temperaturas elevadas e precipitação bem distribuída ao longo do ano (Klein 1980, Leite \& Klein 1990, Roderjan et al. 2002, Pires et al. 2005).

Nas faixas dos 600-700 m e 800-900 $\mathrm{m}$ os valores de riqueza foram intermediários, mas não menos relevantes, sendo apenas um pouco inferiores ao observado nos 400-500 m. Isto demonstra que, a despeito de ocorrer um aumento nas restrições ambientais, como a redução na temperatura e no espaço de vida pelo menor porte da vegetação, na medida em que se eleva a altitude, outras variáveis ambientais acabam por compensar as restrições, proporcionando habitat adequado para um rico conjunto de espécies. Uma das variáveis ambientais mais influentes no desenvolvimento da comunidade epifítica de encostas intermediárias é o aumento na insolação das copas e no interior da floresta (Leme 1993), devido à forte declividade, à existência de clareiras, e ao próprio porte mais reduzido das árvores.

A faixa altitudinal dos $1.000-1.100 \mathrm{~m}$ foi a que apresentou a menor riqueza na encosta estudada. Esta tendência foi também observada para a comunidade arbórea no mesmo local (Blum 2006), decorrente principalmente da influência do clima mais frio, que acaba por restringir a ocorrência de muitas espécies de patamares mais baixos. Um fator secundário que também pode influenciar na menor riqueza de epífitas neste patamar altitudinal é a menor oferta de substrato, tendo em vista que as árvores são mais baixas e com copas menores nestas altitudes, em virtude do solo raso e da declividade acentuada.

Demonstrando a riqueza de microambientes existentes e sua grande influência na distribuição espacial das epífitas, verificou-se um reduzido número de espécies com ocorrência em todas as quatro faixas altitudinais. Foi o caso de plantas com elevada plasticidade, indiferentes às condições climáticas, como Tillandsia geminiflora, Rhipsalis teres, Rumohra adiantiformis, Pecluma recurvata, 
Pleopeltis hirsutissima, Serpocaulon catharinae e Vittaria lineata, todas muito comuns em todos os pisos altitudinais avaliados e também com ampla dispersão em maior escala geográfica, tendo sido registradas em todas as formações florestais relacionadas à Floresta Ombrófila Densa no Paraná, desde as florestas de restinga da Planície Litorânea até a zona ecotonal com a Floresta Ombrófila Mista, no Primeiro Planalto (Schütz-Gatti 2000, Petean 2002, 2009, Kersten \& Silva 2005, Kersten \& Kuniyoshi 2006).

O limite climático entre os tipos $\mathrm{Cfa}$ e $\mathrm{Cfb}$, situado na região dos 700 m s.n.m. e influente sobre as associações florísticas arbóreas (Blum \& Roderjan, 2007), parece determinar também diferenciações na distribuição das epífitas, com razoável montante de espécies ocorrendo somente abaixo desta cota, provavelmente por não suportar as temperaturas médias mais frias do clima $\mathrm{Cfb}$, que inclui a possibilidade de geadas (ainda que remotas nesta região). De outro lado, algumas espécies aparentemente não apreciam as temperaturas mais elevadas do clima Cfa, e foram encontradas somente acima da cota dos $800 \mathrm{~m}$.

Dentre o grupo de elevada restrição ambiental figuram algumas espécies que ocorreram somente nas extremidades da encosta estudada. Destas, as que foram exclusivas da faixa 400-500 m, podem ser consideradas típicas da formação Submontana, caso de Monstera adansonii, Racinaea spiculosa, Cattleya forbesii, Dichaea pendula e Lockartia lunifera, todas também registradas por Schütz-Gatti (2000) e Petean (2009), que estudaram trechos de Floresta Ombrófila Densa Submontana em municípios próximos. Dentre as espécies restritas às altitudes elevadas, faixa entre 1.000 e $1.100 \mathrm{~m}$, destacam-se Nidularium campo-alegrensis, também observada por Petean (2002) e Scheer \& Mocochinski (2009) em altitudes elevadas de outras serras paranaenses, e Grobya galeata, cuja presença foi igualmente registrada por Petean (2002) na Serra do Marumbi e por Kersten (2006) em Piraquara, já no Primeiro Planalto.

Ao longo da encosta, verificou-se uma tendência gradual de redução da similaridade florística entre os patamares altitudinais, na medida em que se aumenta o desnível de altitude. Deste modo, enquanto os patamares adjacentes $400-500 \mathrm{~m}$ e $600-700 \mathrm{~m}$ foram quase $60 \%$ similares, a similaridade entre $400-500 \mathrm{~m}$ e $1.000-1.100 \mathrm{~m}$ caiu pela metade, sendo de apenas $30 \%$. O patamar dos 800-900 m parece abrigar uma região de transição florística, uma vez que apresenta valores relativamente semelhantes de similaridade com seus patamares adjacentes, tanto acima quanto abaixo.

De um modo geral, a comparação entre a composição florística dos quatro patamares altitudinais da Serra da Prata e de outras seis áreas no PR e SP resultou em valores baixos de similaridade. As duas áreas que apresentaram maior similaridade com algum patamar altitudinal da Serra da Prata foram Morro da Mina e Salto Morato, cerca de $40 \%$ similares ao patamar dos 400-500 m. Tal índice pode ser ainda considerado relativamente baixo, por tratar-se de áreas relativamente próximas e com a mesma fitofisionomia. Por outro lado, a similaridade com a comunidade do Parque Carlos Botelho-SP alcançou valor relativamente próximo, a despeito deste se encontrar a cerca de $150 \mathrm{~km}$ ao norte da área de estudo. Demonstrando a importância da altitude na diferenciação da composição de espécies, verificou-se que a área mais similar ao patamar dos 1.000-1.100 m da Serra da Prata é a formação altomontana da Serra do Marumbi, situada acima dos $1.000 \mathrm{~m}$ s.n.m.

Como já ressaltado por Kersten (2006, 2010), é bastante provável que a baixa similaridade entre as áreas se deva em grande parte pela influência da variabilidade de paisagens na composição de espécies da família Orchidaceae (diversidade gama), a qual tende a formar associações diferenciadas em cada área, mesmo existindo semelhança das condicionantes ambientais e relativa proximidade em termos de distância. Por se tratar da família dominante nas comunidades epifíticas de qualquer floresta tropical (Madison 1977, Gentry \& Dodson 1987b, Benzing 1990), a sua diversidade possui grande peso na composição da similaridade entre floras de diferentes locais.

Para ilustrar este aspecto pode-se fazer uma breve avaliação sobre a composição das orquidáceas epifíticas da Serra da Prata, Morro da Mina e Salto Morato. Em conjunto estas três áreas somaram um total de 156 espécies de Orchidaceae, mas apenas $15(9,6 \%)$ foram registradas nas três áreas e, por outro lado, 107 (68,6\%) se caracterizaram por terem sido encontradas em apenas uma das áreas. A Reserva Morro da Mina, situada a $27 \mathrm{~km}$ ao norte da Serra da Prata, apresentou apenas 23 espécies de Orchidaceae em comum com a Serra da Prata. Já a Reserva Salto Morato, $62 \mathrm{~km}$ a noroeste, tem em comum 27 espécies com a área estudada.

\section{Agradecimentos}

Aos pesquisadores Jorge L. Waechter, Rodrigo A. Kersten, Carina Kozera, Marise P. Petean e Alexandre Uhlmann, pelas correções e sugestões; a Ruddy T. Proença, Juarez Michelotti, Daros A. T. da Silva, Joachim Graf Neto, Rafael D. Zenni, Marcelo Brotto, Bernardo Blum, Adriane Neuhaus e Lucas Pontes, pelo auxílio em campo; aos taxonomistas Andrea F. da Costa (Vriesea), Eric C. Smidt e Werner S. Mancinelli (Orchidaceae), Fernando B. de Matos, Jovani B. de Souza Pereira e Vinícius A. O. Dittrich (Pteridophyta), Marcos Nadruz (Araceae) e Mayara K. Caddah (Melastomataceae); à equipe do Museu Botânico Municipal de Curitiba, pelo auxílio na identificação botânica; ao ICMBIO, pela licença de pesquisa no PARNA Saint-Hilaire/Lange.

\section{Referências Bibliográficas}

ANGIOSPERM PHYLOGENY GROUP-APG III. 2009. An update of the Angiosperm Phylogeny Group classification for the orders and families of flowering plants: APG III. Bot. j. Linn. Soc. 161:105-121. http://dx.doi. org/10.1111/j.1095-8339.2009.00996.x

ATHAYDE, S.F. 1997. Composição florística e estrutura fitossociológica em quatro estágios sucessionais de uma Floresta Ombrófila Densa Submontana como subsídio ao manejo ambiental, Guaraqueçaba, PR. Dissertação de mestrado, Universidade Federal do Paraná, Paraná.

BENAVIDES, A.M., DUQUE, A.J., DUIVENVOORDEN, J., VASCO, G. A. \& CALLEJAS, R. 2005. A first quantitative census of vascular epiphytes in rainforests of Colombian Amazonia. Biodivers. Conserv. 14:739-758. http://dx.doi.org/10.1007/s10531-004-3920-9

BENZING, D.H. 1989. Vascular epiphytism in America. In Tropical rainforest ecosystems, Ecosystems of the world (H. Lieth \& M.J.A. Werger, eds). Amsterdan, v.14b, p.133-154.

BENZING, D.H. 1990. Vascular epiphytes. Cambridge University Press, New York. http://dx.doi.org/10.1017/CBO9780511525438

BENZING, D.H. 1995. Vascular epiphytes. In Forest Canopies (M.D. Lowman \& N.M. Nadkarni, eds). Academic Press, San Diego, p.225-254.

BENZING, D.H. 2000. Bromeliaceae-Profile of an adaptative radiation. Cambridge University Press, New York. http://dx.doi.org/10.1017/ CBO9780511565175

BLUM, C.T. 2006. A Floresta Ombrófila Densa na Serra da Prata, Parque Nacional Saint-Hilaire/Lange, PR-caracterização florística, fitossociológica e ambiental de um gradiente altitudinal. Dissertação de mestrado, Universidade Federal do Paraná, Paraná.

BLUM, C.T. \& RODERJAN, C.V. 2007. Espécies indicadoras em um gradiente da Floresta Ombrófila Densa na Serra da Prata, Paraná, Brasil. Rev. Bras. Biociên. 5(2):873-875.

BLUM, C.T., RODERJAN, C.V. \& GALVÃO, F. 2011. O clima e sua influência na distribuição da Floresta Ombrófila Densa na Serra da Prata, Morretes, Paraná. Floresta 41(3):589-598. 
BORGO M. \& SILVA S.M. 2003. Epífitos vasculares em fragmentos de Floresta Ombrófila Mista, Curitiba, Paraná, Brasil. Rev. Bra. Bot. 26(3):391-401. http://dx.doi.org/10.1590/S0100-84042003000300012

BREIER T.B. 2005 O epifitismo vascular em florestas do sudeste do Brasil. Tese de doutorado, Universidade Estadual de Campinas, São Paulo.

BUZATtO, C.R., SEVERO, B.M.A. \& WAECHTER, J.L. 2008. Composição florística e distribuição ecológica de epífitos vasculares na Floresta Nacional de Passo Fundo, Rio Grande do Sul. Iheringia, Bot. 63(2):231-239.

CERVI, A.C. \& BORGO, M. 2007. Epífitos vasculares no Parque Nacional do Iguaçu, Paraná-Levantamento preliminar. Fontqueria 55:415-422.

CURCIO, G.R. 1992. Caracterização e gênese de Podzólicos VermelhoAmarelos e Cambissolos da porção sul da Serra do Mar, PR. Dissertação de mestrado, Universidade Federal do Paraná, Paraná.

DETTKE, G.A., ORFRINI, A.C. \& MILANEZE-GUTIERRE, M.A. 2008. Composição florística e distribuição de epífitas vasculares em um remanescente alterado de Floresta Estacional Semidecidual no Paraná, Brasil. Rodriguésia 59(4):859-872.

DITTRICH, V.A.O., KOZERA, C. \& SILVA, S.M. 1999. Levantamento florístico de epífitos vasculares no Parque Barigüi, Paraná, Brasil. Iheringia, Bot. 52:11-22.

DITTRICH, V.A.O., WAECHTER, J.L. \& SALINO, A. 2005.Species richness of pteridophytes in a montane Atlantic rain forest plot of Southern Brazil. Acta Bot. Bras. 19(3):519-525. http://dx.doi.org/10.1590/S010233062005000300013

ENGWALD, S. 1999. Diversität und Ökologie der Epiphyteneines Berg-und einesTieflandregenwaldes in Venezuela-EinevergleicheAnalyse.Tese de doutorado, Universidade de Bonn, Alemanha.

FONTOURA, T., COSTA, A. \& WENDT, T. 1991. Preliminary checklist of the Bromeliaceae of Rio de Janeiro State, Brazil. Selbyana 12:5-45.

FONTOURA, T., SYLVESTRE, L.S., VAZ, A.M.S. \& VIEIRA, C.M. 1997. Epífitas vasculares, hemiepífitas e hemiparasitas da Reserva Ecológica de Macaé de Cima. In Serra de Macaé de Cima: diversidade florística e conservação em Mata Atlântica (H.C. Lima \& R.R. Guedes-Bruni, eds). Editora do Jardim Botânico do Rio de Janeiro, Rio de Janeiro, p.89-102.

FUNDAÇÃO BIODIVERSITAS. 2005. Lista da flora brasileira ameaçada de extinção. http://www.biodiversitas.org.br/florabr/lista_florabr.pdf (ultimo acesso em 30/06/2011).

GENTRY, A.H. \& DODSON C.H. 1987a.Contribution of non trees to species richness of a tropical rain forest.Biotropica 19:149-156. http://dx.doi. org/10.2307/2388737

GENTRY, A.H. \& DODSON, C.H. 1987b. Diversity and biogeography of neotropical vascular epiphytes. Ann. Miss. Bot. Gard. 74:205-233. http:// dx.doi.org/10.2307/2399395

GIONGO, C. \& WAECHTER J.L. 2004. Composição florística e estrutura comunitária de epífitos vasculares em uma floresta de galeria na Depressão Central do Rio Grande do Sul. Rev. Bra. Bot. 27:563-572. http://dx.doi. org/10.1590/S0100-84042004000300015

GIULIETTI, A.M., RAPINI, A., ANDRADE, M.J.G., QUEIROZ, L.P. \& SILVA, J. M.C. 2008. Plantas raras do Brasil. Conservação Internacional, Belo Horizonte.

GONÇALVES, C.N. \& WAECHTER, J.L. 2003. Aspectos florísticos e ecológicos de epífitos vasculares sobre figueiras isoladas no norte da planície costeira do Rio Grande do Sul. Acta Bot. Bra. 17:89-100.

GUAPYASSÚ, M.S. 1994. Caracterização fitossociológica de três fases sucessionais de uma Floresta Ombrófila Densa Submontana, Morretes, Paraná. Dissertação de mestrado, Universidade Federal do Paraná, Paraná.

HARTSHORN, G.S. \& HAMMEL, B.E. 1994. Vegetation types and floristic patterns. In La Selva: ecology and natural history of a neotropical rain forest (L.A. McDade, K.S. Bawa, H.A. Hespenheide\& G.S. Hartshorn, eds). The University of Chicago Press, Chicago, p.73-89.

HERTEL, R.J.G. 1949. Contribuição à ecologia de flora epífita da Serra do Mar (vertente oeste) do Paraná. Tese de concurso à livre docência, Faculdade de Filosofia, Ciências e Letras da Universidade do Paraná, Paraná.
IBISCH, P. 1996. Neotropische Epiphyten diversität, das Beispiel Bolivien. Martina Galunder-Verlag, Wiehl.

INGRAM, S.W., FERREL-INGRAM, K. \& NADKARNI, N.M. 1996. Floristic composition of vascular epiphytes in a neotropical cloud forest, Monteverde, Costa Rica. Selbyana 17:88-103.

INSTITUTO AGRONÔMICO DO ESTADO DO PARANÁ - IAPAR. 1978. Cartas climáticas básicas do estado do Paraná. IAPAR, Londrina.

INSTITUTO BRASILEIRO DE GEOGRAFIA E ESTATÍSTICA IBGE. 1992. Manual Técnico da Vegetação Brasileira. Fundação Instituto Brasileiro de Geografia e Estatística, Rio de Janeiro.(Série Manuais Técnicos em Geociências, n. 1).

INSTITUTO PARANAENSE DE DESENVOLVIMENTO ECONÔMICO E SOCIAL - IPARDES. 1991. Diagnóstico Físico Ambiental da Serra do Mar, Área Sul. Instituto Paranaense de Desenvolvimento Econômico e Social, Curitiba.

INTERNATIONAL UNION FOR CONSERVATION OF NATURE IUCN. 2011. IUCN Red List of Threatened Species. Version 2011.1. http:// www.iucnredlist.org/apps/redlist/search (ultimo acesso em 30/06/2011).

KAEHLER, M. 2008. Bromélias. In As montanhas do Marumbi (N.L.P. Alves, ed). Edição do Autor, Curitiba, p.325-329.

KERSTEN, R.A. \& KUNIYOSHI, Y.S. 2006. Epífitos vasculares na bacia do alto Iguaçu, Paraná-Composição florística. Est. Biologia 28:55-71.

KERSTEN, R.A. \& SILVA, S.M. 2002. Florística e estrutura do componente epifítico vascular em floresta ombrófila mista aluvial do rio Barigüi, Paraná, Brasil. Rev. Bra. Bot. 25(3):259-267. http://dx.doi.org/10.1590/ S0100-84042002000300002

KERSTEN, R.A. \& SILVA, S.M. 2005. Florística e estrutura de comunidades de epífitas vasculares da planície litorânea. In História natural e conservação da Ilha do Mel (M.C.M. Marques \& R.M. Britez, eds). Editora UFPR, Curitiba, p.125-143.

KERSTEN, R.A. \& SILVA, S.M. 2006. The floristic compositions of vascular epiphytes of a seasonally inundated forest on the coastal plain of Ilha do Mel Island, Brazil. Rev. Biol. Trop. 54(3):935-942.

KERSTEN, R.A. 2006. Epifitismo vascular na bacia do Alto Iguaçu, Paraná. Tese de doutorado, Universidade Federal do Paraná, Paraná.

KERSTEN, R.A. 2010. Epífitas vasculares-Histórico, participação taxonômica e aspectos relevantes, com ênfase na Mata Atlântica. Hoehnea 37(1):9-38.

KERSTEN, R.A., KUNIYOSHI, Y.S. \& RODERJAN, C.V. 2009. Epífitas vasculares em duas formações ribeirinhas adjacentes na bacia do rio Iguaçu, Terceiro Planalto Paranaense. Iheringia, Bot. 64(1):33-43.

KLEIN, R.M. 1980. Ecologia da flora e vegetação do vale do Itajaí (continuação). Sellowia 32:1-389.

LABIAK, P.H. \& PRADO, J. 1998. Pteridófitas epífitas da Reserva Volta Velha, Itapoá, Santa Catarina, Brasil. Bol. Inst. Bot. 11:1-79.

LACERDA, A.E.B. 1999. Levantamento florístico e estrutural de vegetação secundária em área de contato da Floresta Ombrófila Densa e Mista, PR. Dissertação de Mestrado, Universidade Federal do Paraná, Paraná.

LEITE, P. F. 2002. Contribuição ao conhecimento fitoecológico do sul do Brasil. Rev. Ciênc. Amb. 24:51-73.

LEITE, P. \& KLEIN, R.M. 1990. Vegetação. In Geografia do Brasil: região Sul. Instituto Brasileiro de Geografia e Estatística-IBGE, Rio de Janeiro, v.2, p.113-150.

LEME, E.M.C. 1993. Bromélias na natureza. Marigo Comunicação Visual, Rio de Janeiro.

LEME, E.M.C. 1998. Canistropsis, bromélias da Mata Atlântica. Editora Salamandra, Rio de Janeiro.

LEME, E.M.C. 2000. Nidularium, bromélias da Mata Atlântica. Editora Sextante, Rio de Janeiro.

LIMA, H.C. \& GUEDES-BRUNI R.R. 1997. Diversidade de plantas vasculares na Reserva Ecológica de Macaé de Cima. In Serra de Macaé de Cima: diversidade florística e conservação em Mata Atlântica (H.C. Lima \& R.R. Guedes-Bruni, eds). Editora do Jardim Botânico do Rio de Janeiro, Rio de Janeiro, p.29-63. 
LOPES, O.F. 1987. O Granito Sin-Tectônico Cubatãozinho: petrogênese e evolução geológica. In $3^{\circ}$. Simpósio Sulbrasileiro de Geologia. Sociedade Brasileira de Geologia, Curitiba, v.1, p.390-398.

MADISON, M. 1977. Vascular epiphytes: their systematic occurrence and salient features. Selbyana 2:1-13.

MANCINELLI, W.S. \& ESEMANN-QUADROS, K. 2007. Levantamento de epífitos vasculares em quatro forófitos em diferentes altitudes no Morro da Tromba, SC. Cad. Inic. Pesq. 9:205-208.

MARTINELLI, G., VIEIRA, C.M., GONZALEZ, M., LEITMAN, P., PIRATININGA, A., COSTA, A.F. \& FORZZA, R.C. 2008. Bromeliaceae da mata atlântica brasileira: lista de espécies, distribuição e conservação. Rodriguésia 59(1):209-258.

MUELLER-DOMBOIS, D. \& ELLENBERG, H. 1974. Aims and methods of vegetation ecology. John Wiley \& Sons, New York.

NADKARNI, N. 1984. Epiphyte biomass and nutrient capital of a neotropical elfin forest. Biotropica 16(4):249-256. http://dx.doi.org/10.2307/2387932

NIEDER, J., ENGWALD, S., KLAWUN, M. \& BARTHLOTT, W. 2000. Spatial distribution of vascular epiphytes (including hemiepiphytes) in a Lowland Amazonical Rain Forest (Surumoni Crane Plot) of Southern Venezuela. Biotropica 32(3):385-396

NUNES-FREITAS, A.F. 2004. Bromeliáceas da Ilha Grande: variação interhabitats na composição, riqueza e diversidade da comunidade. Tese de doutorado, Universidade do Estado do Rio de Janeiro, Rio de Janeiro.

PACIENCIA, M.L.B. 2008. Diversidade de pteridófitas em gradientes de altitude na Mata Atlântica do Estado do Paraná, Brasil. Tese de doutorado, Universidade de São Paulo, São Paulo.

PARANÁ (Estado). Secretaria de Estado do Meio Ambiente e Recursos Hídricos-SEMA. 1995. Lista vermelha de plantas ameaçadas de extinção no estado do Paraná. SEMA/GTZ, Curitiba.

PETEAN, M.P. 2002. Florística e estrutura dos epífitos vasculares em uma área de Floresta Ombrófila Densa Altomontana no Parque Estadual do Pico do Marumbi, Morretes, Paraná, Brasil. Dissertação de mestrado, Universidade Federal do Paraná, Paraná

PETEAN, M.P. 2009. As epífitas vasculares em uma área de Floresta Ombrófila Densa em Antonina, PR. Tese de doutorado, Universidade Federal do Paraná, Paraná.

PIRES, P.T.L., ZILLI, A.L. \& BLUM, C.T. 2005. Atlas da Floresta Atlântica no Paraná, área de abrangência do Programa Proteção da Floresta Atlântica. SEMA, Programa Proteção da Floresta Atlântica-Pró-Atlântica, Curitiba.

PRIDGEON, A.M. \& CHASE, M.W. 2001. A phylogenetic reclassification of Pleurothallidinae (Orchidaceae). Lindleyana 16:235-271. PMid:21669661. http://dx.doi.org/10.2307/3558390

PRIDGEON, A.M., SOLANO, R. \& CHASE, M.W. 2001. Phylogenetic relationships in pleurothallidinae (Orchidaceae): combined evidence from nuclear and plastid DNA sequences. Am. J. Bot. 88(12):2286-2308.

REGINATO, M. \& GOLDENBERG, R. 2007. Análise florística, estrutural e fitogeográfica da vegetação em região de transição entre as Florestas Ombrófilas Mista e Densa Montana, Piraquara, Paraná, Brasil. Hoehnea 34(3):349-364.

REIS, J.R. M. \& FONTOURA, T. 2009. Diversidade de bromélias epíftas na Reserva Particular do Patrimônio Natural Serra do Teimoso-Jussari, BA. Biota Neotrop. 9(1): http://www.biotaneotropica.org.br/v9n1/pt/ abstract?article+bn01209012009 (último acesso em 03/08/2010).

RODERJAN, C.V. 1994. O gradiente da Floresta Ombrófila Densa no Morro do Anhangava, Quatro Barras, PR-Aspectos climáticos, pedológicos e fitossociológicos. Tese de doutorado, Universidade Federal do Paraná, Paraná.
RODERJAN, C.V., GALVÃO, F., KUNIYOSHI, Y.S. \& HATSCHBACH, G.G. 2002. As unidades fitogeográficas do estado do Paraná, Brasil. Rev. Ciênc. Amb. 24:75-92.

ROGALSKI, J.M. \& ZANIN E.M. 2003. Composição florística de epífitos vasculares no estreito de Augusto César, Floresta Estacional Decidual do Rio Uruguai, RS, Brasil. Rev. Bra. Bot. 26:551-556.

SANTOS, A.C.L. 2008. Composição florística e estrutura da comunidade de epífitas vasculares associadas a trilhas no Parque Estadual das Fontes do Ipiranga, São Paulo, SP, Brasil. Dissertação de mestrado, Instituto de Botânica, São Paulo.

SCHEER, M.B. \& MOCOCHINSKI, A.Y. 2009. Florística vascular da Floresta Ombrófla Densa Altomontana de quatro serras no Paraná Biota Neotrop. 9(2): http://www.biotaneotropica.org.br/v9n2/pt/ abstract?article+bn00609022009 (último acesso em 04/08/2010).

SCHORN, L.A. \& GALVÃO, F. 2001. Fitossociologia em ambientes compartimentalizados de uma Floresta Ombrófila Densa Montana. Rev. Est. Amb. 3(2-3):86-97.

SCHÜTZ-GATTI, A.L. 2000. O componente epifítico vascular na Reserva Salto Morato, Guaraqueçaba-PR. Dissertação de mestrado, Universidade Federal do Paraná, Paraná

SIEDLECKI, K.N., PORTES, M.C.O. \& CIELO FILHO, R. 2003. Proposta de adequação dos limites do Parque Nacional Saint Hilaire/Lange (Serra da Prata)-estado do Paraná. In II Simpósio de áreas protegidas-Conservação no Âmbito do Cone Sul. Universidade Católica de Pelotas, Pelotas.

SILVA, F.C. 1994. Composição florística e estrutura fitossociológica da floresta tropical ombrófila da encosta atlântica no município de Morretes (Paraná). Bol. Pesq. Florestal 18-19:31-49.

SMITH, A R., PRYER, K M., SCHUETTPELZ, E., KORALL, P., SCHNEIDER, H. \& WOLF, P.G. 2006. A classification for extant ferns. Taxon 55:705-731. http://dx.doi.org/10.2307/25065646

SPECIESLINK. 2010. Sistema de informação distribuído para coleções biológicas: a integração do SpeciesAnalyst e do SinBiota (FAPESP). Centro de Referência em Informação Ambiental-CRIA. http://splink. cria.org.br/ (último acesso em 25/07/2010).

STEEGE, H. \& CORNELISSEN, J.H.C. 1989. Distribution and ecology of vascular epiphytes in Lowland rain forest of Guiana. Biotropica21(4):331-339. http://dx.doi.org/10.2307/2388283

TROPICOS. 2009. Tropicos.org. Missouri Botanical Garden. http://www. tropicos.org/ (último acesso em 02/07/2010).

TRYON, R.M. \& TRYON, A.F. 1982. Ferns and allied plants, with special reference to Tropical America.Springer-Verlag, New York.

WAECHTER, J.L. 1986. Epífitos vasculares da mata paludosa do Faxinal, Torres, Rio Grande do Sul, Brasil. Iheringia, Bot. 34:39-49.

WAECHTER, J.L. 1992. O epifitismo vascular na planície costeira do Rio Grande do Sul. Tese de doutorado, Universidade Federal de São Carlos, São Carlos.

WETTSTEIN, R.R.V. 1970. Aspectos da vegetação do Sul do Brasil. Edgard Blücher, São Paulo.

WORLD CHECKLIST OF SELECTED PLANT FAMILIES. 2010. The Board of Trustees of the Royal Botanic Gardens, Kew.http:// apps.kew.org/wcsp/prepareChecklist.do?checklist=selected families\%40\%40024240120101755773 (ultimo acesso em 22/07/2010).

ZULOAGA, F.O., MORRONE, O. \& BELTRANO, M.J. 2008. Catálogo de las plantas vasculares Del Cono Sur (Argentina, Sur de Brasil, Chile, Paraguay e Uruguay). Monog. Syst. Botan. 107:1-3486. 
